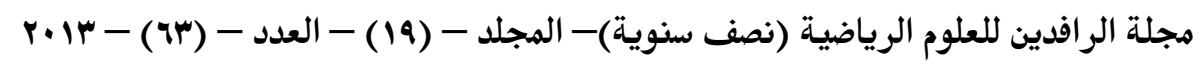

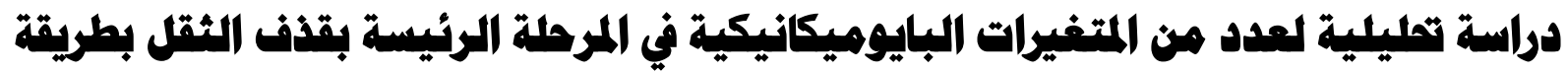 \\ الزوطقة
}

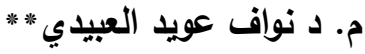

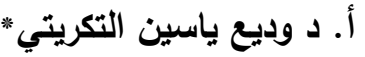

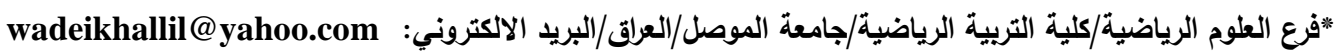

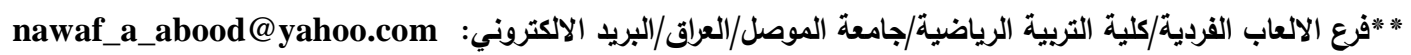

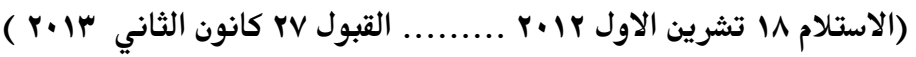

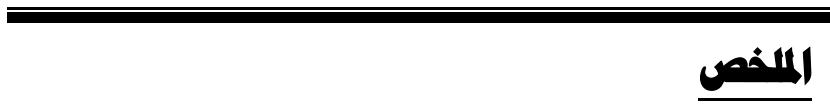

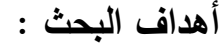

ا - التعرف إلى قيم عدد من المتغيرات الكينماتيكية والكينتيكية وقيم دالة القوة - الزمن في المرحلة الرئيسة بقذف الثقل بطريقة ألزحلقة .

r - إيجاد العلاقة بين المتغيرات الكينماتيكية وبين المتغيرات الكينتيكية في المرحلة الرئيسة بقذف الثقل بطريقة ألزحلقة .

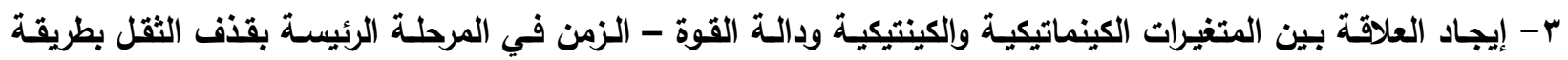
ألزحلقة

استخدم الباحثان المنهج الوصفي بأسلـوب العلاقات لملاعمته لأهداف وطبيعة البحث ، اختـار الباحثّان العينة

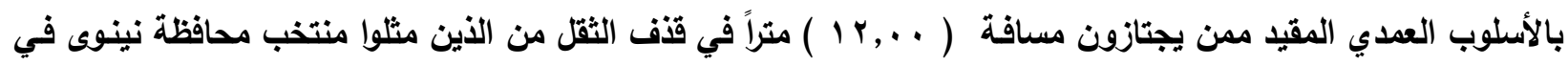

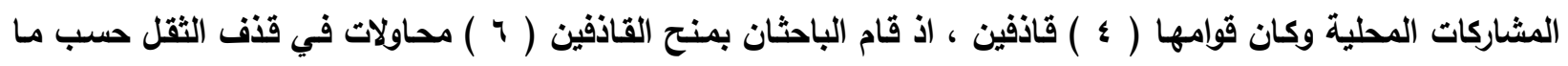

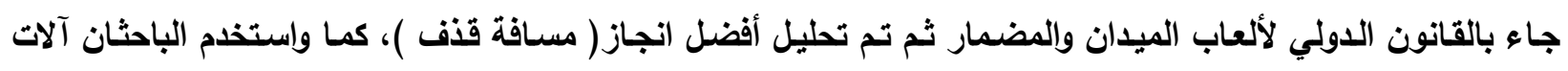

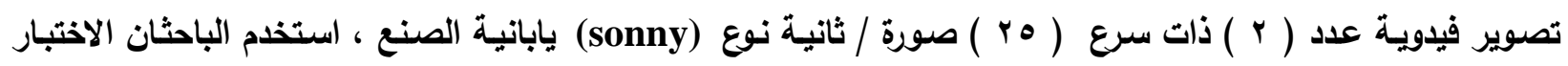

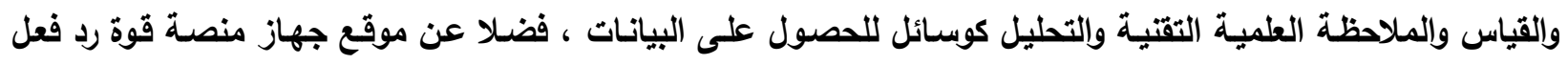

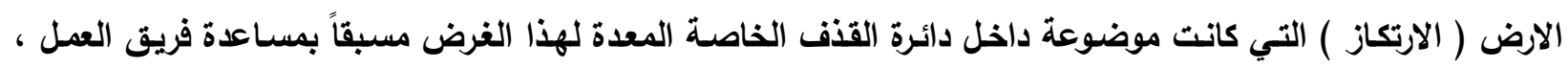

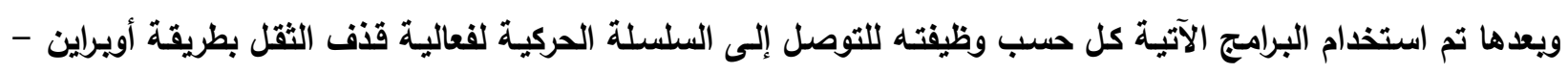

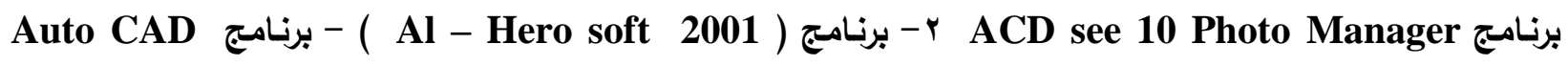

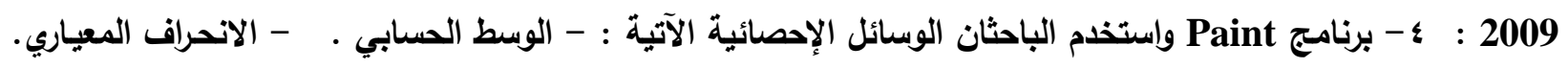

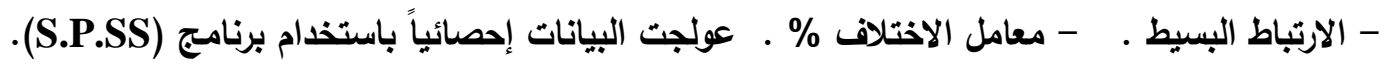

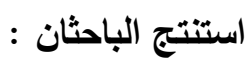

ا - وجود علاقة معنوية بين المتغيرات الكينماتيكية إذ مثلت متغيرات مركز ثقل كتلة الجسم والإزاحة والارتفاع والسرعة

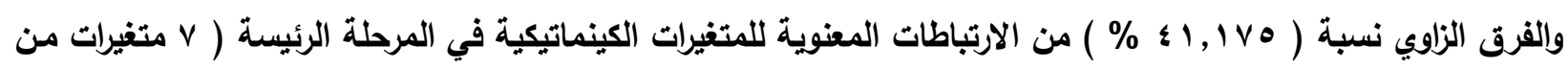
(أصل IV )

r- وجود علاقة معنويـة بين المتغيرات الكينتيكية في الزخم الأفقي والطاقة الحركية الأفقيـة ومحصلة الزخم والطاقة

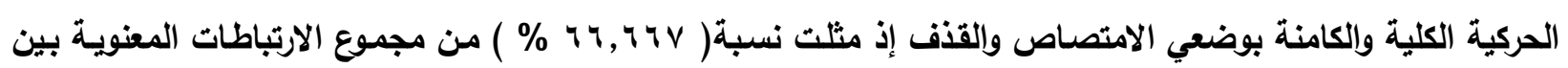
المتغيرات الكينتيكية ( 7 متغيرات من أصل و و ) ) .

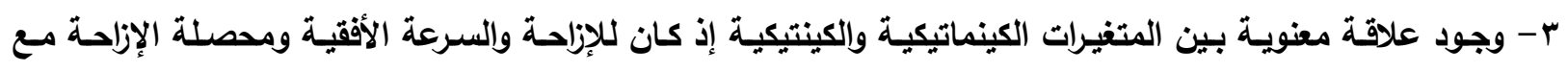

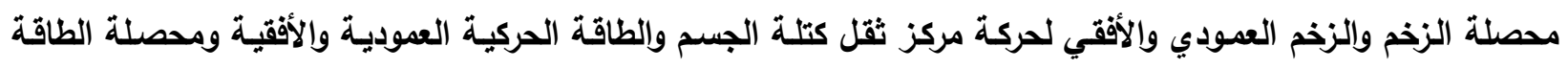


ع - وجود علاقة معنوية بين متغيرات دالة القوة - الزمن إذ كان لزمن الوصول إلى أقصى قوة رد فعل وزمن استخدامها

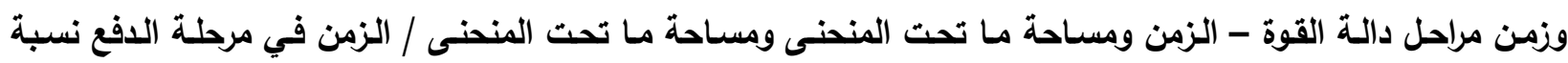

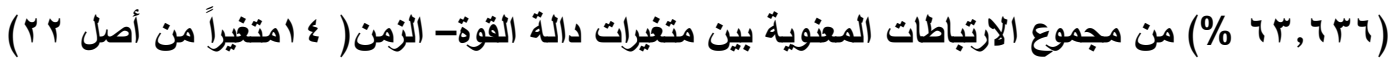

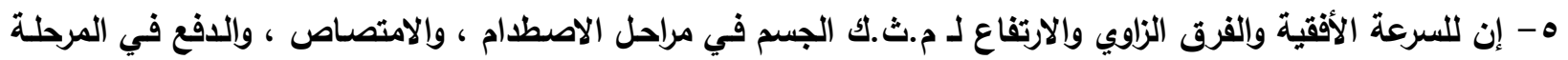

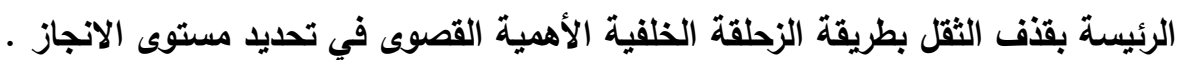

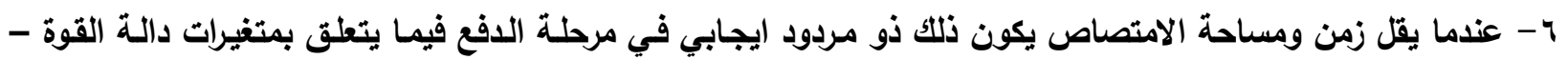
الزمن - (الزمن

- V إن بزيادة الزمن الكلي في المرحلة الرئيسة بقذف الثثل بطريقة الزحلقة الخلفية سوف بزيد بذلك قيم مساحة ما تحت

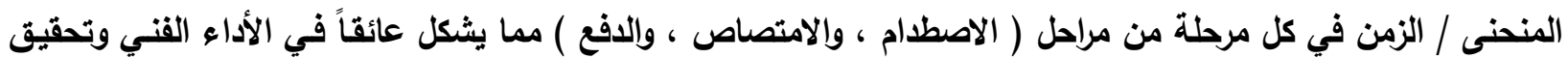

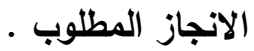

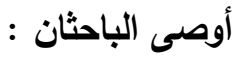
ا - التأكيد على انجاز أقصى قوة في مرحلة الدفع المقرون بعرعة الأداء لتحقيق أفضل انجاز في قنف الثقل .

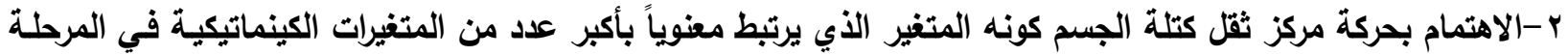
الرئيسة بقذف الثقل بطريقة أويراين . ب- ب- تطوير السرعة الزاوية للجسم في مرطلة الافع لانعكاساتها الايجابية على المسافة الحقيقية لمسار الثقل في الطيران .

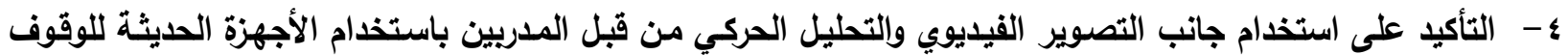

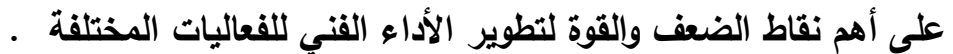
ه- الانتقاء المناسب للقاذفين ويما يحقق الانجاز من مواصفات جسمانية وطول للأراع والطول الكلي للجسم في فعالية قذف الثقل .

צ- على المدربين والعاملين في المجال الرياضي الاهتمام بمقار تسليط القوة في مرحلة الاصطام وتقليل زمن الامتصاص قلر الإمكان للاستفادة من هذا الإجراء في مرحطة الدفع .

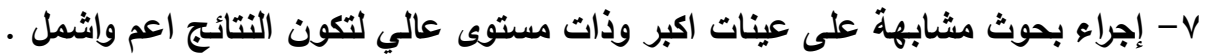

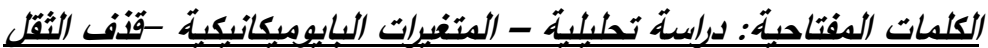

\section{ANALYTICAL STUDY OF NUMBER OF MECHANIC VARIABLES IN THE MAIN SHOT - PUT PHASE ACCORDING TO ABAKING GLIDE} Dr. Nawaf Owaid Abood Al-obaidy

Prof. Dr. Wadei . Yassen . Altikriti

\section{ABSTRACT}

\section{Research's aims:}

1. To realize the values of certain variables kinematics, kinetic, and as well as force-time function in the main phase of shot-put according to baking guide.

2 . To find the correlation between the kinematics variables and between kinetic variables and between force-time function variables for the main phase of shot-put according to baking guide.

3. To find the correlation between the kinematics and kinetics variables, and between the kinematics and force-time function variables in the main phase of shot-put according to baking guide . 


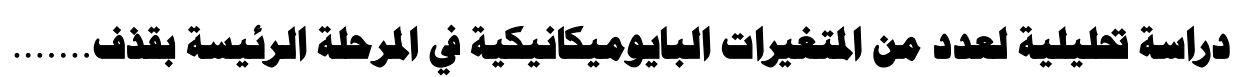

The researchers has applied the descriptive method for its convenience with the nature of the research. The research sample has consisted of (4) shot putters who represented the Nineva team in the shot-put activity, Each putter was given (6) trials according to the international law of track and field games. All the trials were filmed and the best trial was analyzed The researcher has used tests, measurement, scientific technical observation and analysis as means for data collecting. The sample subjects have been filmed by using three video cameras each of which films a part of the activity as well as using the platform of measuring ground reaction prepared for this purpose. as well as using programs such like : ACD See 10 Photo program Manager, Al-Hero soft 2001 program, Auto CAD 2009 program and Paint program, After the analysis was achieved, data were statistically handled by applying SPSS application. Statistical means applied in the research are as follows: (arithmetic mean, standard deviation, Person simple correlation coefficient, variance coefficient and percentage).

\section{Research's Conclusions:}

1. There were significant relationship between the kinematics variables body mass center of gravity's variables in terms of displacement, distance, height and velocity have represented $\mathbf{4 1 . 1 7 5 \%}$ of the significant correlations of the kinematics variables in the main phase (7 variables out of 17).

2. There were significant relationship between the kinetics variables in horizontal thrust, horizontal energy power thrust limited, energy power kidney and implicit in condition the absorb and throw out have represented $66.666 \%$ of the significant correlations of the kinetics variables (6 variables out of 9).

3. There were significant relationship between the kinematics and the kinetics variables at the displace and horizontal velocity, and displace limited, and thrust limited, vertical thrust and horizontal ,to movement body mass center of gravity's and, vertical and horizontal energy power, and energy power limited represented $23.77 \%$ of the significant correlations between the kinematics and the kinetics variables (6 variables out of 26).

4. While the time and the area of absorb will be slightly that will be positive yield in the push phase to do with concern liberty force - time variables .

7 . If increase the total time in the main phase to shot-put with method backing glide will be growth the rate of under curve area - time td each phase of phases (hit-absorb-push) which pigeon block in the technical performance to inquiry needed achievement

The researchers has recommended the following:

1. Confirmation on the performance as much as possible achievement of force generation associated with velocity during the pushing phase to attain the best achievement in shot-put .

2 Taking care of the movement of body mass center of gravity as being the variable that significantly correlated with the largest number of kinematics variables in the main stage of weight shot according to Baking glide .

3 . Developing the body angular velocity during the pushing phase for its positive reactions on real distance of the shot flight trajectory.

4. Confirmation to use video filming sight and motion analysis from coaching by using new equipment to stand up of the important point of power and feeble to developing technical performance for deferent influences .

5 . Suitable choosing of the putters according achievement variables such as bodily physical specifics and arm length and total body length in shut-putt .

6. To worker and coaching in sports take care about quantity instruction power in hit phase and fewness of absorb time prospects destiny to conclude this make in push phase. 

inclusive.

\section{Keywords: Analytical Study - Biomechanic Variables - Shot Phase}

: 1

إن استخدام الأجهزة الحديثة والوسائل العلمية المتطورة فضلاً عن التقنيات المتقدمة التي تسهم في تطبيق نتائج البحوث الميدانية والمختبرية قد سهل مهمة الباحثين والمدربين في اختبار آلية علمية تتسم بالدقة والموضوعية للقياس والتقويم وتوجيه الأداء الفني للمهارات الرياضية الذي يتم بتحليل الحركة تحليلاً دقيقاً ، فقد أكدت الدراسات والبحوث على أهمية التقويم المستمر باستخدام أنظمة ميكانيكية للقياس العلمي الدقيق لتحسين مستوى الأداء ، "وأن هذه الأنظمة الميكانيكية باستخدام الحاسوب الآلي أصبحت من تكنولوجيا التدريب الرياضي الذي يمكن من خلاله

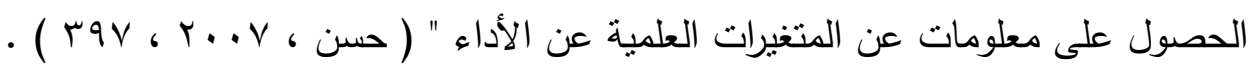

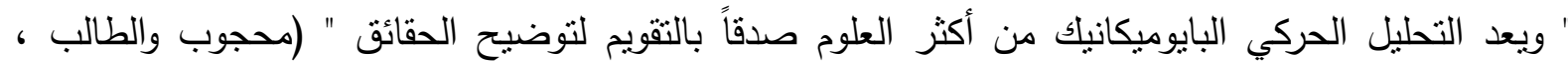
VAV والحركة الأقل جودة ، ويوضح لنا الفروق بين الحركات الجيدة التي هي على درجات متقاربة "كما أن المستويات العالية لا يمكن أن تتطور إلا من خلال التحليل الحركي " (محجوب ، ، 199 ، 10 ) ) ، وكذلك يمكّن المدرب من هن الحصول على مجموعة كبيرة من المعلومات الفنية للمهارة الحركية التي تفيد في التعليم والتدريب بصورة جيدة وتطوير

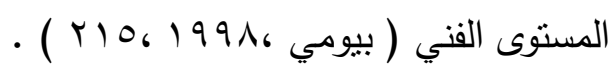

ونظراً لتطور فعالية قذف التقل فقد استمر الباحثون في التقصي من أجل حل المشكلات المتعلقة بالأداء المهاري والانجاز وذللك بتشخيصها ثم علاجها وقد تتاولت بحوث ودراسات كثيرة الجانبين البدني والمهاري للارتقاء بهذين الجانبين من خلال إعداد برامج تعليمية وتدريبية كثيرة ، أما الجانب الميكانيكي المرتبط بمتطلبات الأداء ولاسيما ما ودراه يتعلق بوضعي القوة والقذف واللتان تعدان الأكثر أهمية في مراحل هذه الفعالية فقد تضمنت دراسات قليلة لا تتسم بالثمولية من خلال ربط الجانب الكينماتيكي بالكينتيكي ولاسيما متغيرات دالة القوة - الزمن . أن الهذف الرئيس والأساس في مسابقة القذف مع الاختلاف في طريقتي رميها هو المسافة التي يمكن أن تقطعها الأداة ، ولتحقيق هذا المبدأ يجب نوفر عاملين أساسيين هما مستوى رفيع لطريقة الأداء الفني وعناصر لياقة بدنية وحركية متطورة ، إذ تعتمد المسافة التي يمكن تحقيقها في مسابقات القذف على عدد من العوامل منها ، سرعة Straight - Line ) الإطلاق ، وزاوية الإطلاق ، وارتفاع نقطة الإطلاق ، " وتأثير خط التعجيل المستقبم Acceleration ) ، ومجموع القوى ( Summation of Forces ) ، والتحكم بالتعجيل التقصيري للجزء السفلي من الجسم ( Deceleration of the Lower Body ) ، والاتصال بالأرض ( Contact with the Ground ) " ( Tom , 1986 , 13 ) ، فضلا عن باقي المتغيرات الكينمايتيكية والكينيتيكية قيد الدراسة المزمع البحث فيها . إن فن أداء ( تكنيك ) الدفع يتأثز بقوة دفع القدم الخلفية أولاً ثم الأمامية إلى الأرض إلى أن تتنهي الذراع الرامية

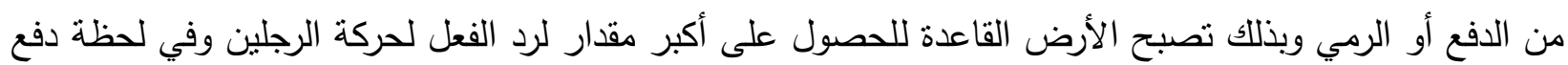
القدم الخلفية للأرض وانتهاء الدفع إلى الأعلى بالذراع يتم رد الفعل للذراع الأمامية للتحرك إلى الأمام من خلال الاستفادة من رد فعل الارتكاز بذل أقصى قوة للرمي والدفع مع الاستفادة الكاملة من النقل الحركي للقوة من القدم إلى البد القاذفة ـ ولعل ابرز الطرائق الثائعة الاستعمال في بطولات العالم الآن هي طريقة الزحلقة الخلفية (أوبراين ) 
(Technique of the shot put O'Brian Method )

مما تقدم يكتسب البحث أهيته من خلال التعرف إلى قيم بعض المتغيرات الكينمايتيكية ومتغيرات دالة القوة - الزمن وعلاقتهما ببعضهما المستحصلة من منصة قياس قوة رد فعل الارض (الارتكاز ) المعدة لهذا الغرض .

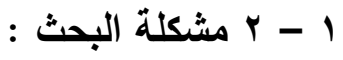

تكمن مشكلة البحث على معرفة مقدار القوة المولدة من جراء رد الفعل للوصول إلى أقصى أنجاز ممكن والاستفادة منها من خلال تسليط هذه القوة على ألأرض ومدى إسهام هذه القوة ابتداءً من الوصول إلى وضع القوة القداء

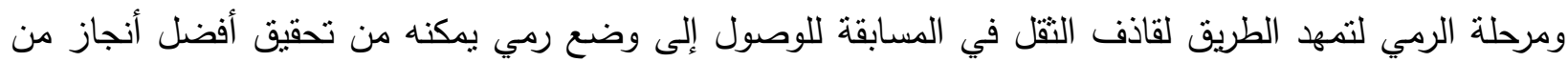

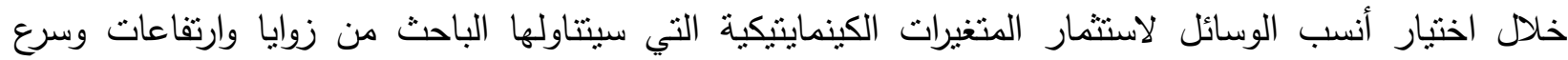
ومسارات لكفاصل الجسم في المرحلة الرئيسة لتحقيق الإنجاز الرقمي العالي في فعالية قذف النقل بطريقة الزحلقة

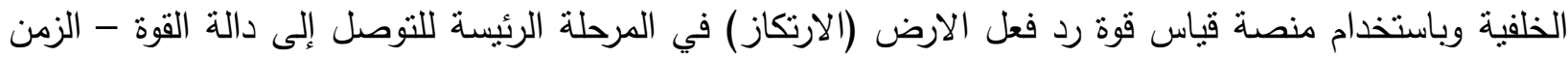
والتي تقيس لأقرب من (1.... ث ) من زمن الحركة والقوة المبذولة والمسلطة على السطح مقدرة بالنيوتن والاستفادة منها في الجانب التدريبي لنطوير ورفع مستوى الإنجاز لدى عينة البحث ومما يعزز لحل مشكلة البحث

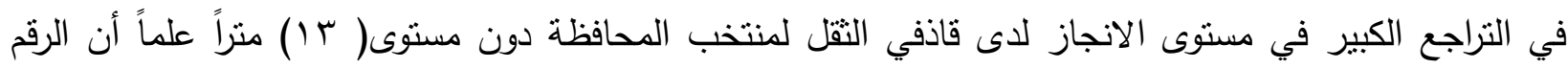

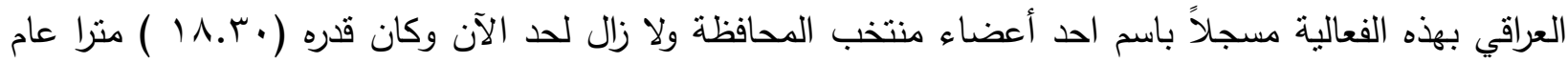
19199 معرفة مقادير القوة الدتولدة في مرحلة قذف النقل ، وان معرفة المتغيرات البايوميكانيكية للاعب بسهم في تحسين

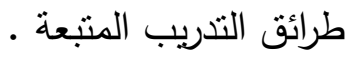

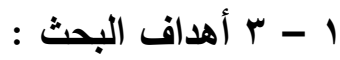

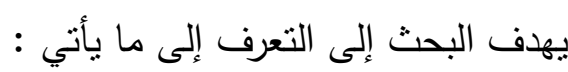

1- قيم عدد من المتغيرات الكينماتيكية والكينتيكية في المرحلة الرئيسة بقذف النقل بطريقة الزحلقة . r- إيجاد العلاقة بين المتغيرات الكينماتيكية ، وبين المتغيرات الكينتيكية في المرحلة الرئيسة بقفف النقل بطريقة الزحلقة . r- العلاقة بين المتغيرات الكينماتيكية والكينتيكية ودالة القوة - الزمن في المرحلة الرئيسة بقذف النقل بطريقة الزحلقة

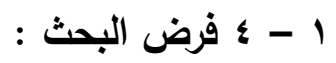

افتزرض الباحثان وجود ارتباط معنوي بين المتغيرات الكينمانيكية والكينتيكية ودالة القوة - الزمن ذاتها ، وبين

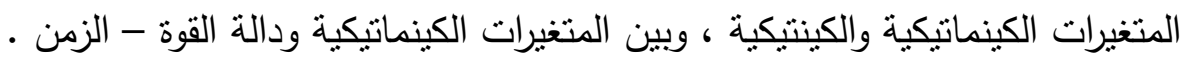

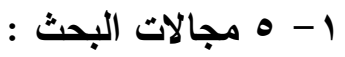
1- ه - 1 المجال البشري : نخبة من قاذفي النقل يمنلون منتخب محافظة نينوى بالعاب الميدان والمضمار في

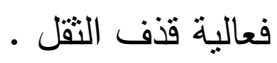

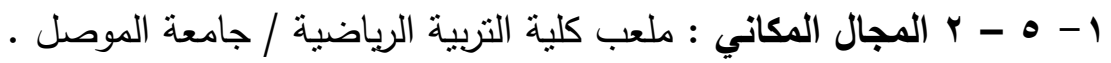

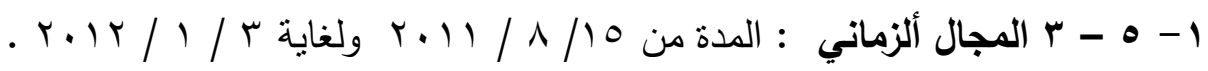




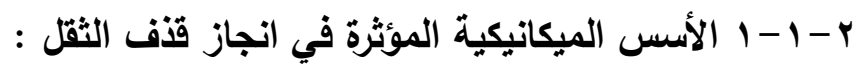

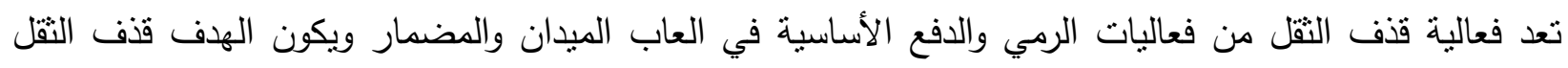

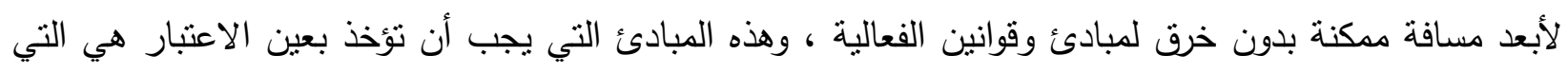

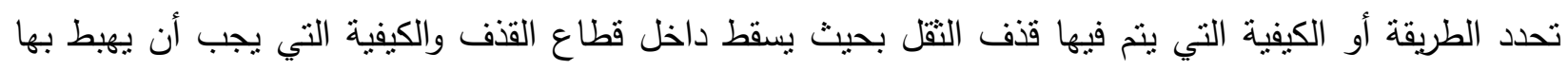

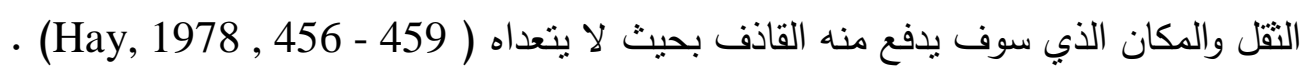
اتقق المختصون على أن إزاحة قذف الثقل تعتمد على الأسس الميكانيكية الآتية :

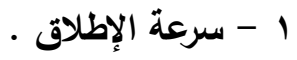

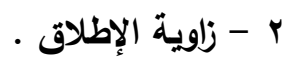

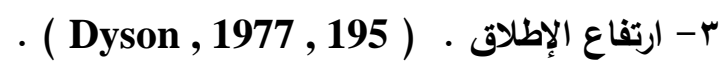

أعلى نقطة لارتفاع للثقل

height point to pot

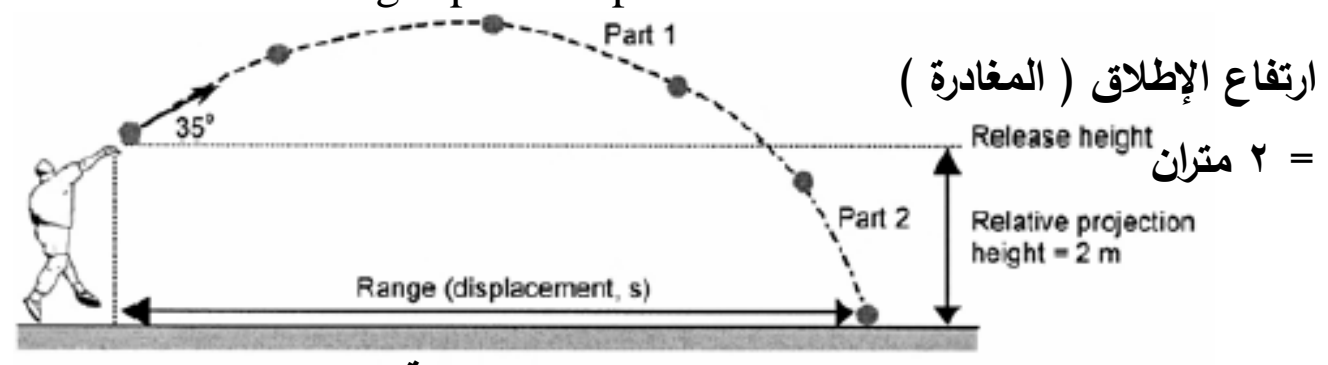

مدى الإزاحة

( Blazevich , 2007 , 29)

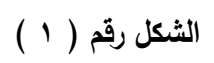

يوضح الأسس الميكانيكية المؤثرة في انجاز قنف الثقل

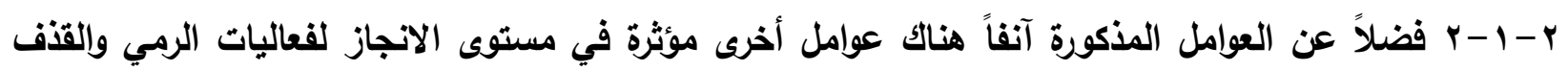
المختلفة وهي : - تأثثر التعجيل الخطي المستقيم ( Straight-Line Acceleration ) : والتي يجب أن يكون عمل جميع القوى

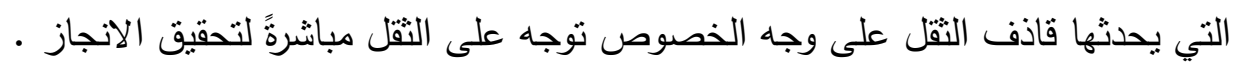

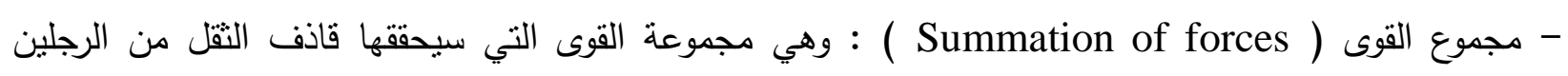
والذراعين بدون حدوث هدر في تلاك القوى والمقدرة على الاستفادة منها في رمية مثالية .

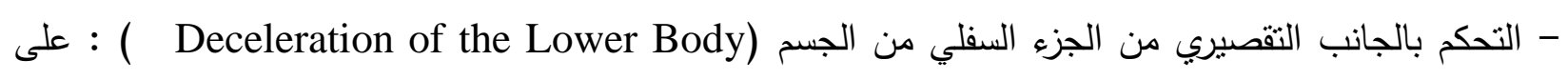
قاذف التقل أن يتمكن من إيقاف سرعة الطرف السفلي والاستفادة من التعجيل الذي أحدثه في الزحلقة لينقلها إلى الى الئ

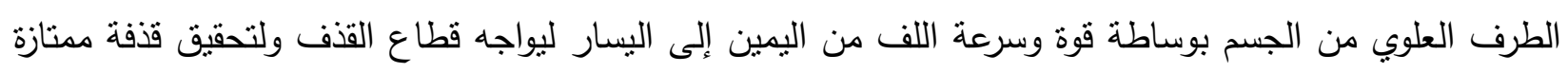
وانجاز جيد.

- الاتصال بالأرض ( Contact with the Ground ) : أن بعض قاذفي الثقل الجيدين والحاصلين على أفضل

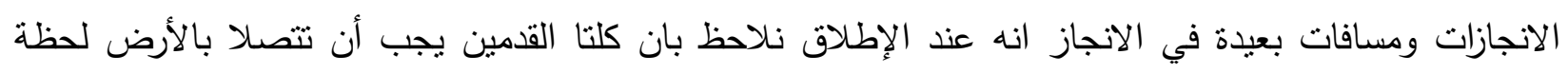

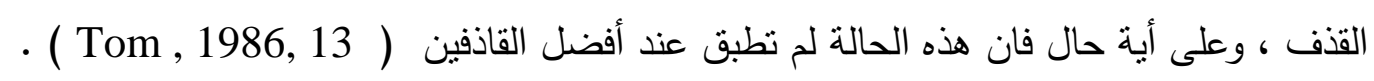




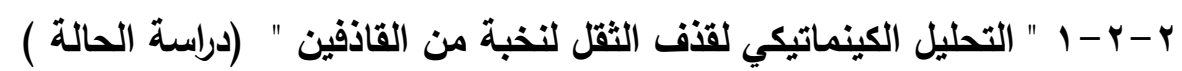

" Kinemataca Analysis of Shot Put in Elite Athletes - Acase study"

( Weimin Liu and Minxuan Wang 2008 )

هداف البحث للتعرف على ما يأني :

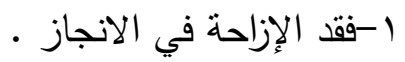

ץ-مرجحة الرجل (السسافة بين مقدم القدم اليمنى والقدم اليسرى قبل لحظة الزحلقة ) ب-ارتفاع الثقل لحظة الإطلاق.

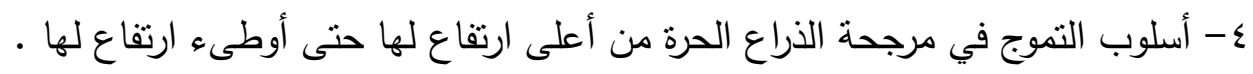

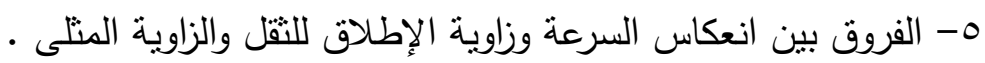

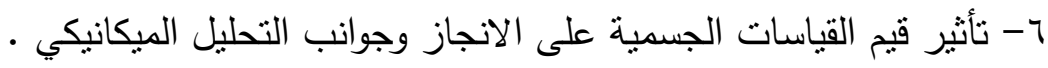

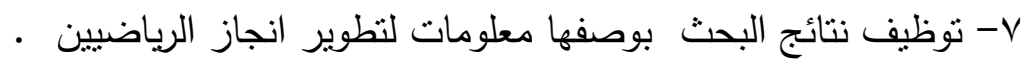

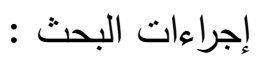

استخدم الباحثان المنهج الوصفي وتككونت عينة البحث من نخبة من قاذفي وقاذفات النقل وسيلة لجمع (النقات

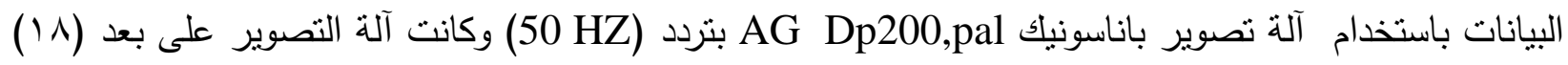

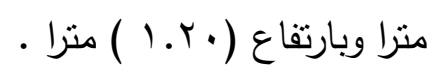

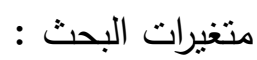

- المسافة الأفقية بين المسقط العمودي للإقل لحظة الإطلاق ولوحة الإيقاف من الأمام . - المسافة بين مقدمة القدم اليمنى والقدم اليسرى قبل لحظة بدء الزحلقة .

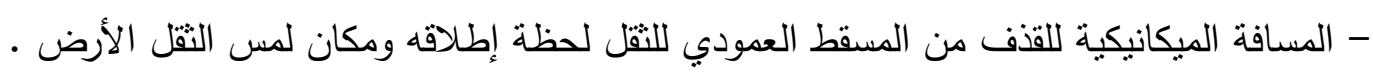

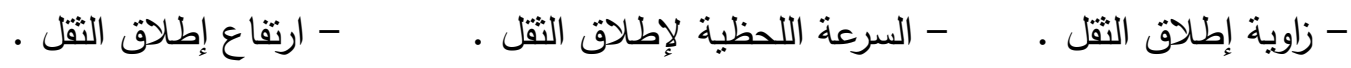

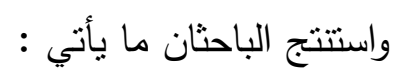

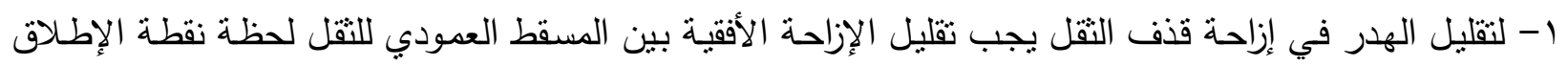
وحافة دائرة القذف الخارجية (لوحة الإيقاف ). r- تقل الإزاحة بوساطة القوة المنتجة من مرجحة الذراع الإنفاع الحرة عكس اتجاه عقرب الساعة ومسار الثقل

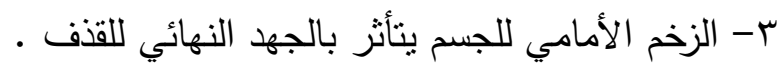
ـ -إن قوة الذراع وحدها ليست المسالة المهمة في القدرة على القذف ولكن لفن الأداء الدور المهم في القدرة على القذف .

0- الإزاحة تقل أيضا باستثمار مرجحة الذراع الفعالة المكافئة للزخم الزاوي للجسم •

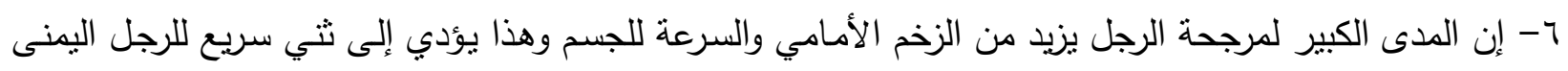

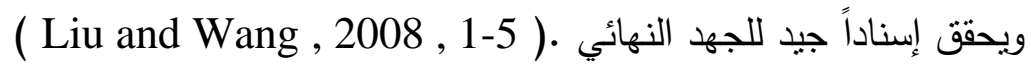




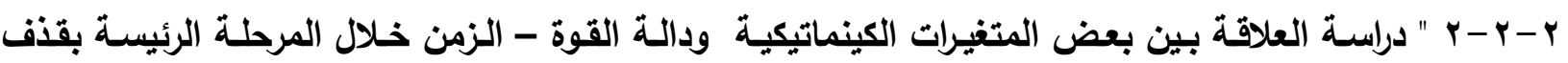

الثقل بطريقة أويراين " ( نواف عويد العبيدي ، 1 · r )

أهداف البحث :

ا- التعرف إلى قيم بعض المتغيرات الكينماتيكيـة والجينومتريـة و دالة القوة - الزمن خـلال المرحلـة الرئيسـة لقذف

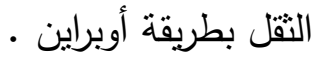

r- التعرف إلى شكل دالة القوة - الزمن للمرحلة الرئيسة بقذف النقل بطريقة أوبراين . r- التعرف إلى المسار الحركي للتقل خلا المرحلة الرئيسة بقذف التقل بطريقة أوبراين ع - إيجاد العلاقة بين بعض المتغيرات الكينماتيكية للمرحلة الرئيسة بقذف التقل بطريقة أوبراين . 0- إيجاد العلاقة بين متغيرات دالة القوة - الزمن للمرحلة الرئيسة بقذف النقل بطريقة أوبراين • ج- إيجاد العلاقة بين المتغيرات الكينماتيكية ومتغيرات دالة القوة - الزمن للمرحلة الرئيسة بقذف النقل بطريقة أوبراين V - بناء نموذج لدالة القوة - الزمن للمرحلة الرئيسة بقذف التقل بطريقة أوبراين لقاذفي النقل العراقيين . استخدم الباحث المنهج الوصفي وذللك لملاءمته وطبيعة البحث ، وتكونت عينة البحث من ( 1 ) قاذفين للتقل ممن مثلكوا المنتخب الوطني العراقي بألعـاب ألميدان والمضـمار في فعاليـة قذف التقل فئة المتقدمين للموسم الرياضي

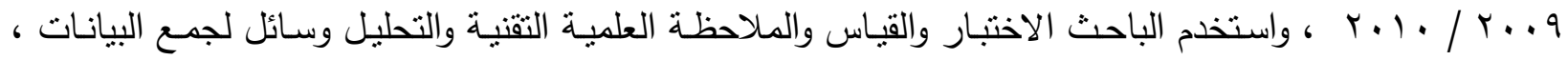
وتم تصوير عينـة البحث من خـل استخدام ثـلاث آلات تصوير فيدويـة ، فضـلاً عن استخدام منصسة قياس قوة رد فعل الأرض المعدة لهذا الغرض بعد الانتهاء من عملية التحليل عولجت البيانات إحصائياً وذلك عن طريق استخدام الحزمـة الإحصـائية SPSS . ( الوسط الحسـي ، والانحراف المعياري ، ومعامل الارتباط البسيط ( بيرسون )( ر)

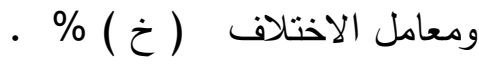

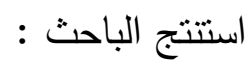
إ-إن قلة زمن ومساحة ما تحت المنحنى لمرحلة الامتصاص ينعكس إيجاباً على متغيرات دالة القوة - الزمن في مرحلة الدفع والقسم الرئيسي بشكل كلي . ץ- وجود علاقة معنوية بين المتغيرات الكينماتيكية مركز تقل كتلة الجسم في متغيرات الإزاحة والمسافة والارتفاع

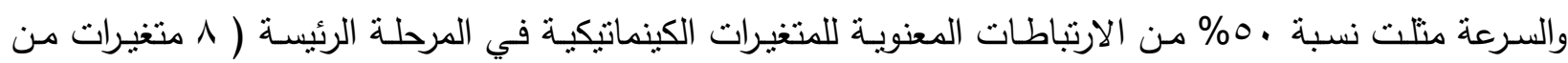

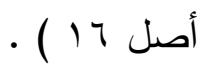
ب- وجود علاقة معنوية بين متغيرات دالة القوة - الزمن إذ كان لـ ( زمن الوصول إلى أقصى قوة رد فعل وزمن استخدامها وزمن مراحل دالة القوة - الزمن ) نسبة ه ٪\% من مجموع الارتباطات المعنوية بين متغيرات دالة القوة-

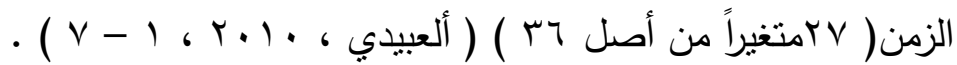
r- 1 (1) منهج البحث

استخدم الباحثان المنهج الوصفي بأسلوب العلاقات لملاعمته لأهداف وطبيعة البحث . 


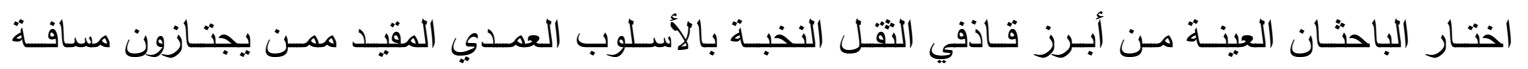

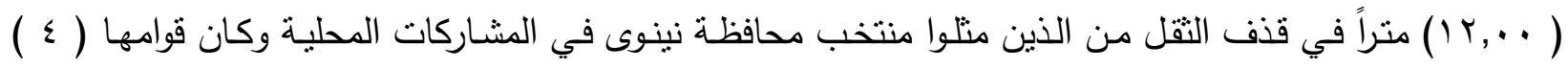
قاذفين" والجدول رقم (1 ) ييين قيم بعض المعالم الإحصائية الخاصة بمواصفات عينة البحث .

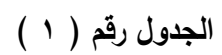

ييين قيم بعض المعالم الإحصائية الخاصة بمواصفات عينة البحث

\begin{tabular}{|c|c|c|c|c|c|c|}
\hline أفضل انجاز للقاذف & ( العمر & 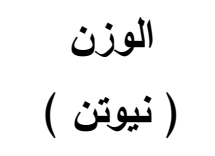 & (كتلة (كفم ) & الطول الكلي & 71 & $ت$ \\
\hline 14,74 & $r$. & $1 \cdot r \cdot, .0$ & 1.0 & 117 & القاذف الأول & 1 \\
\hline IT,YT & rA & $901,0 \mathrm{~V}$ & $9 v$ & 11. & القاذف الثاني & $r$ \\
\hline IT,IT & $r V$ & $99 \cdot, 11$ & 1.1 & IAr & القاذف الثالث & $r$ \\
\hline$I T, \cdot r$ & rq & $11 T V, 97$ & 117 & 194 & القاذف الرابع & $\varepsilon$ \\
\hline IY,V4 & $r \Lambda, 0$ & I. rV, 091 & $1, \varepsilon, v_{0}$ & $110, Y_{0}$ & سَ س & \\
\hline$\cdot, V Y$. & 1,491 & $\Lambda \cdot, r \leqslant \Lambda$ & $\wedge, 1 \wedge$. & $0, V T V$ & $\varepsilon^{ \pm}$ & \\
\hline $0, r \leqslant r$ & $\varepsilon, 0 r$. & $\vee, \Lambda \cdot q$ & $\vee, \Lambda . q$ & $r, .9 V$ & ${ }^{* *} \% \dot{\tau}$ & \\
\hline
\end{tabular}

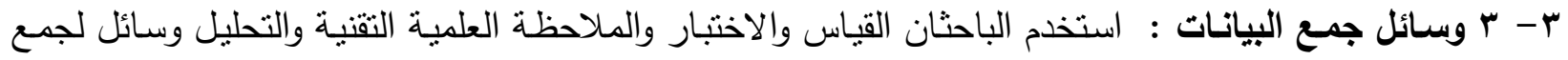
البيانات والحصول على بعض المتغيرات الكينمانيكية .

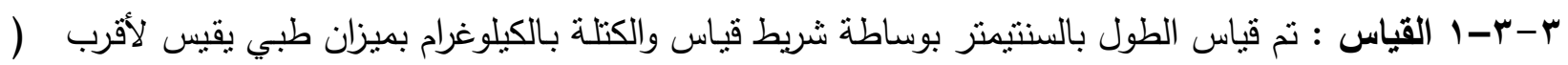

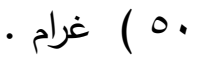

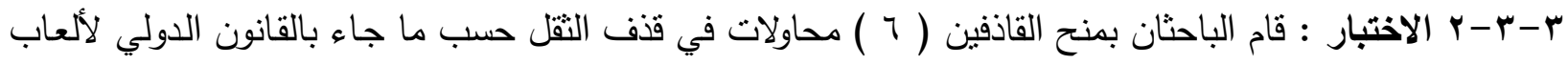

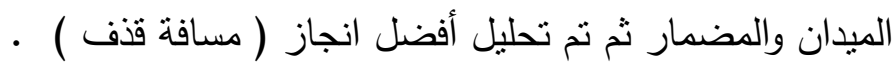
r-r-r الملاحظة العلمية التقنية :

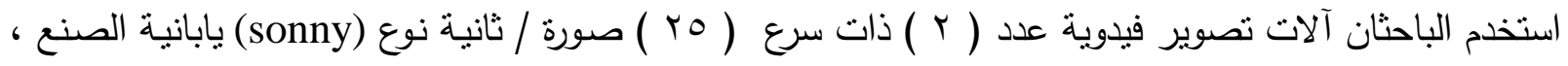

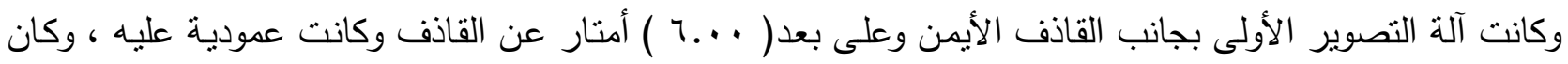

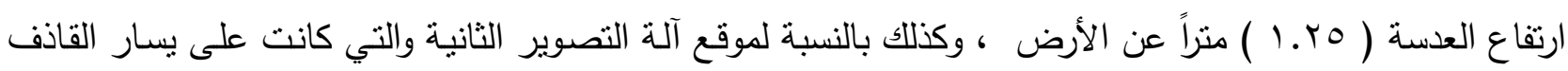
، وكان الغرض منهما استخراج المتغيرات الكينماتيكية الخاصة بكل قاذف عند المرحلة الرئيسة بقذف النقل بطريقة

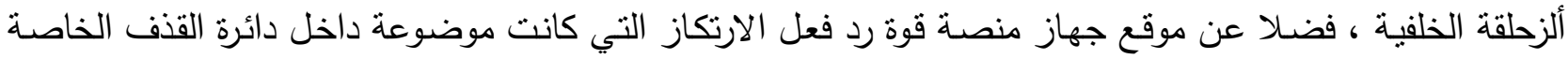
المعدة لهذا الغرض مسبقاً بمساعدة فريق العمل ملحق ( ) 1 ) وحسب المواصفات القانونيـة لهذه الفعالية وتهيئة دائرة

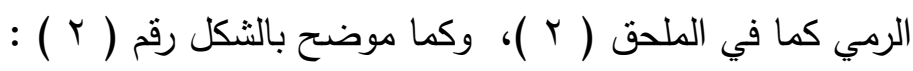




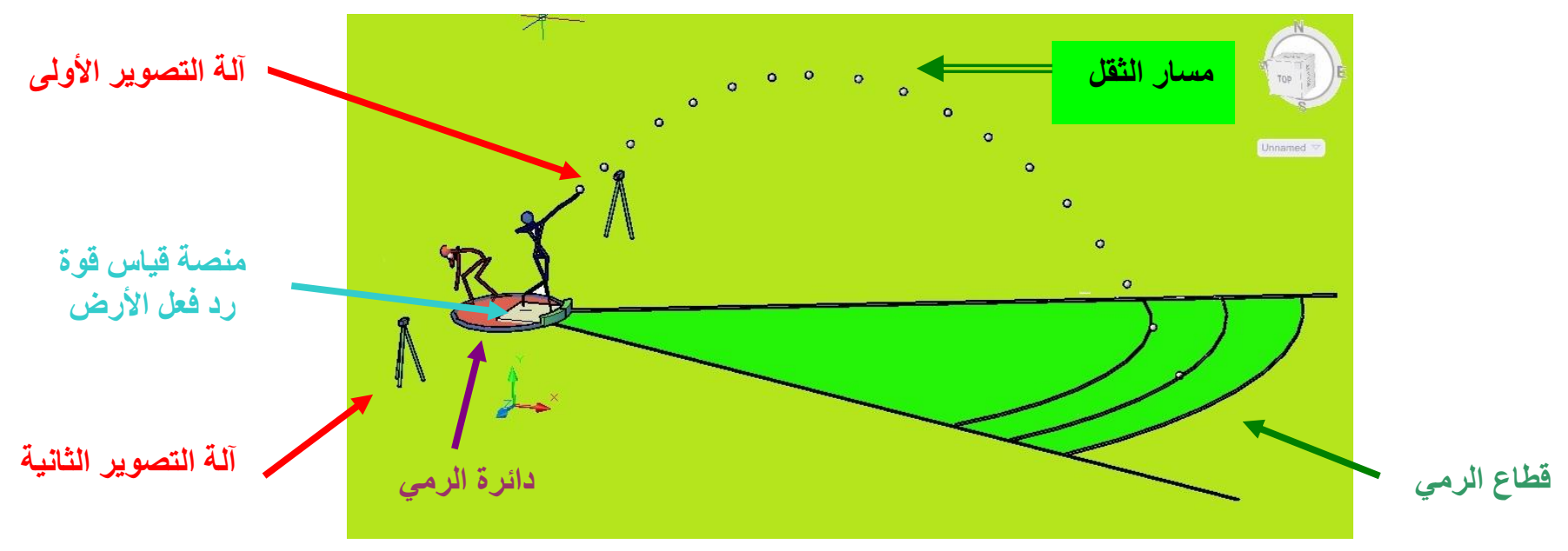

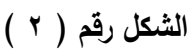

يوضح موقع آلات التصوير ومنصة قياس قوة رد فعل ألارض وطريقة الأداء الفعلي لقنف الثقل بطريقة الزحلقة الخلقية لعينة البحث

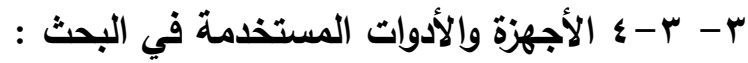
r- r-

- آلة تصوير فيدوية ذات سرعة هب صورة / ثانية عدد ( r ) مع ملحقاتها .

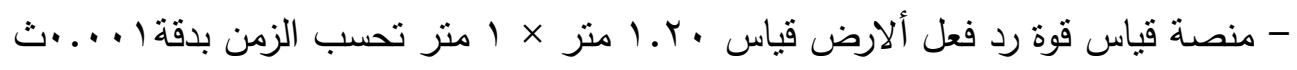

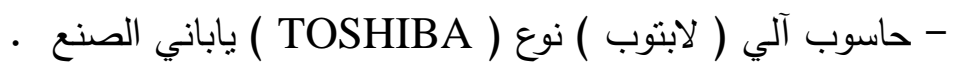

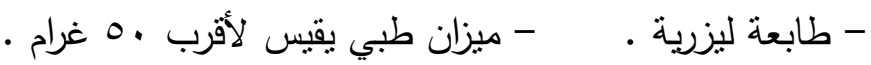
- حاسبة يدوية صينية الصنع استخدمت لاستخراج بعض المعالجات الحسابية .

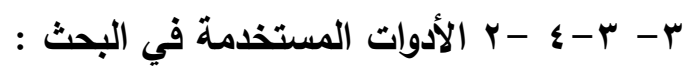

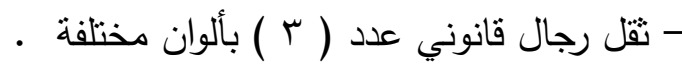

- استمارات قانونية خاصة بفعالية قذف الثقل انظر الملحق ( r ) - أوراق ( A4 ) لتسجيل البيانات الخاصة بالقاذفين من عمر وطول ووزن - شربط قياس - أقراص ليزرية .

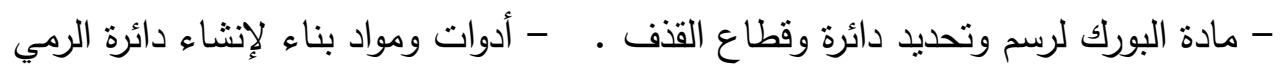

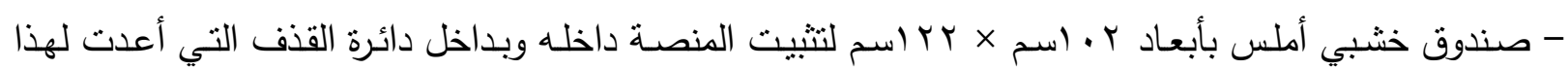

$$
\text { - مقياس الرسم : }
$$

استخدم الباحثان مقياس رسم ( 1 ) متر تم تصويره في منتصف دائرة الرمي مجال حركة القاذف ومنتصف

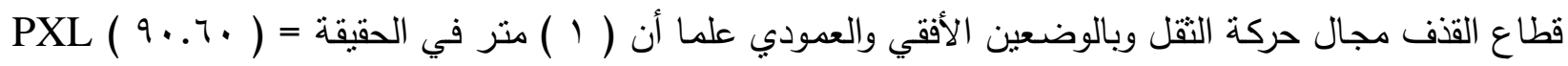

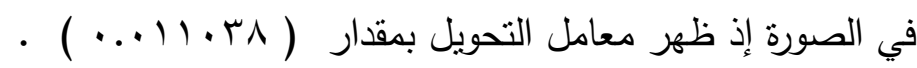
r- ؟ منصة قياس قوة رد فعل ألأرض المستخدمة في هذه الاراسة :

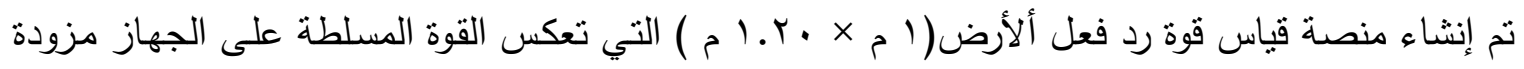

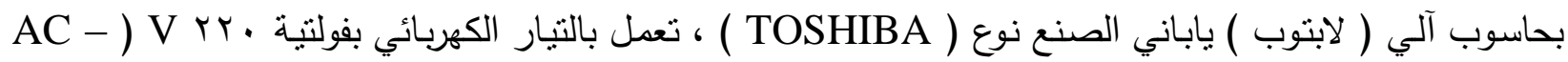

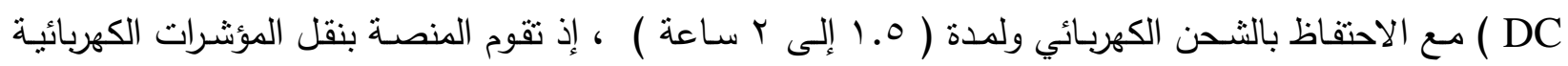




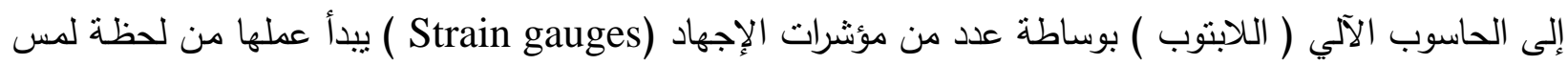

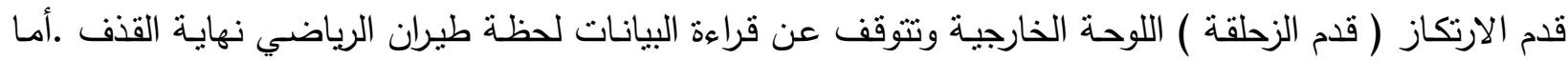

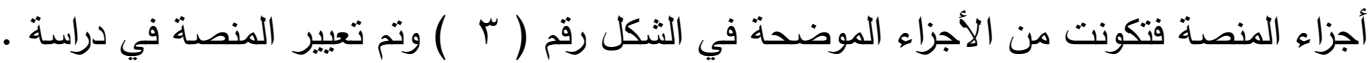

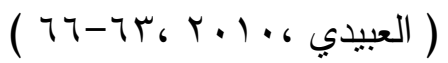

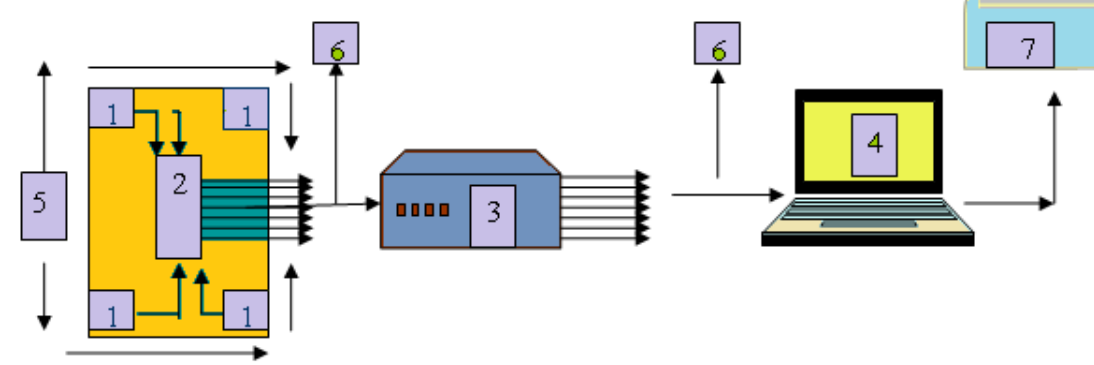

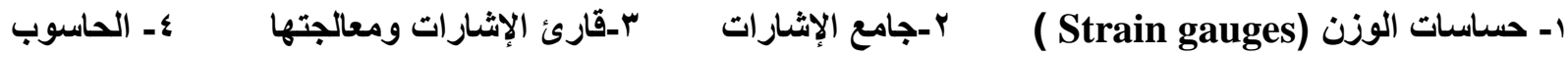
هـمنصة القوة ؟- أسلاك لتوصيل البيانات V- طابعة ليزرية

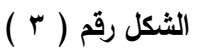

يوضح منصة قياس قوة رد فعل ألأرض وملحقاتها

للتعرف إلى قيم الثكل المستحصل ينم النقر على أيقونة كارت مدى النظر ( View chart ) الموجودة في

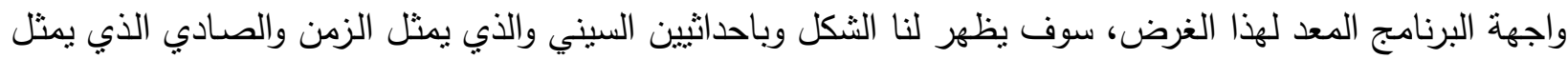
مقدار قوة رد فعل ألأرض المسجلة وكما في الثكل رقم ( ع ) .

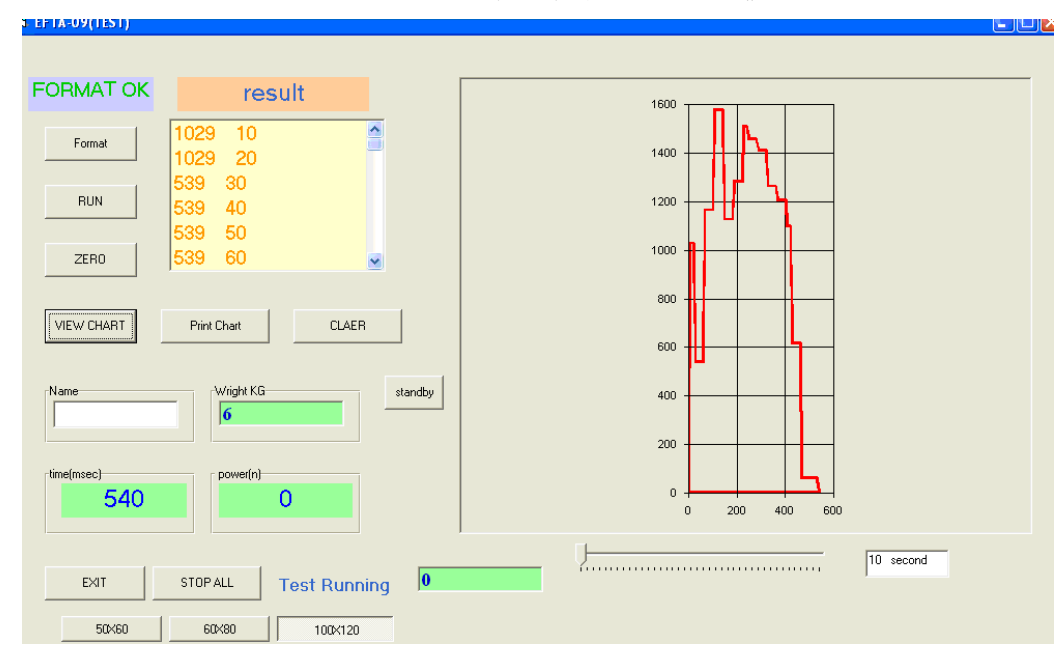

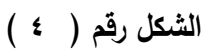

الاحداثي السيني ( الزمن ) والصادي(مقار قوة رد فعل ألأرض المسجلة حسب ظهورها في الحاسوب الآلي

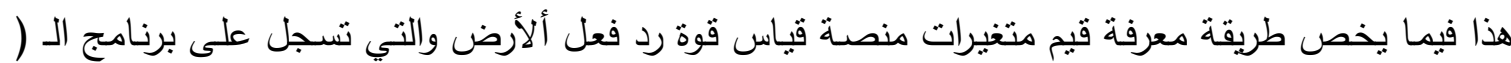
Excel

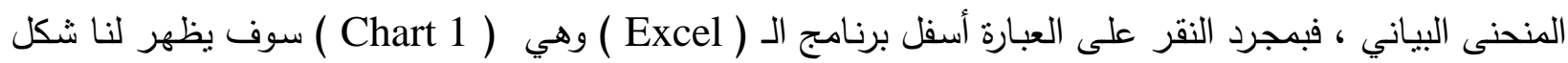

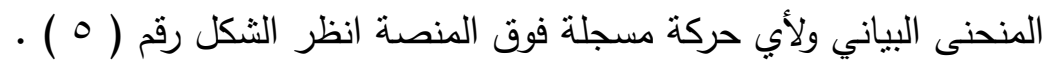




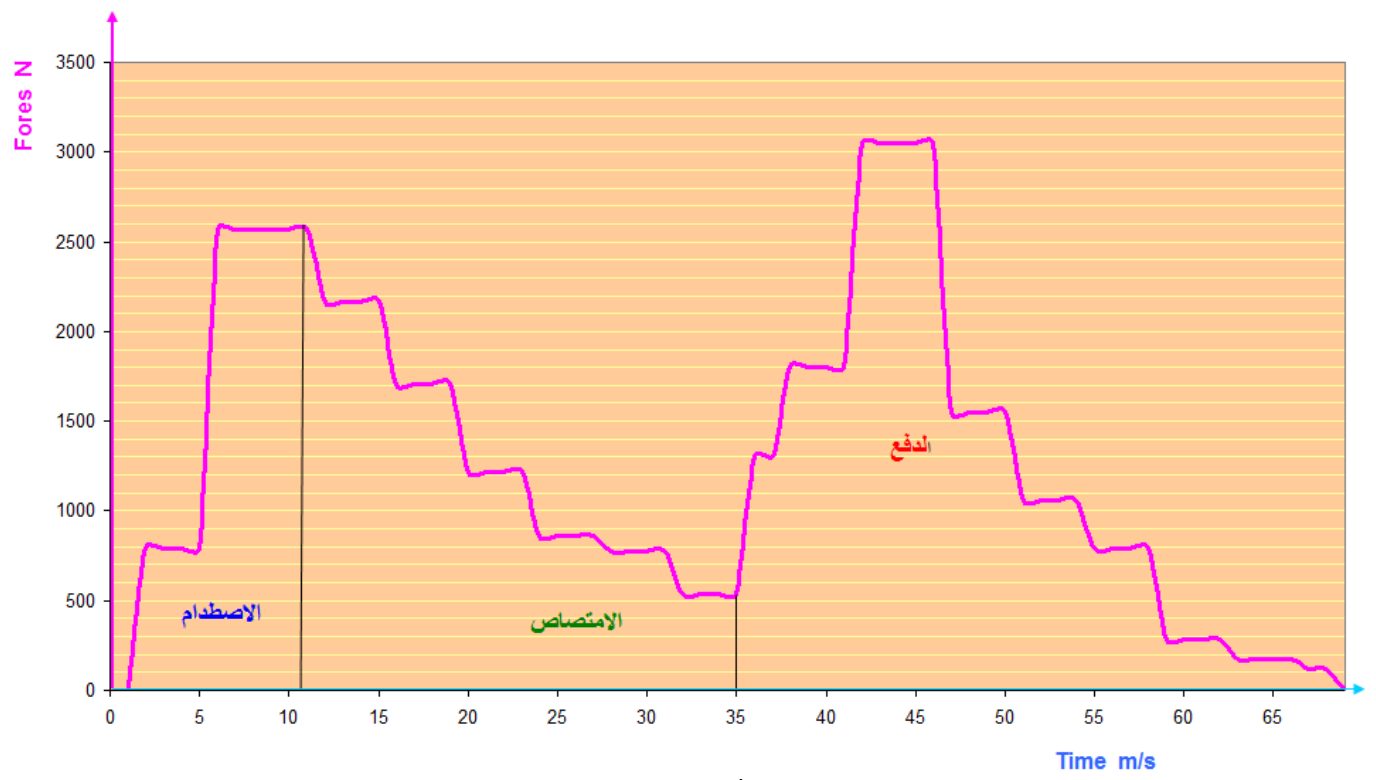

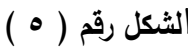

يوضح المنحنى البياني لدالة القوة - الزمن ونظام الوزن لأحد أفراد العينة بالنيوتن حسب ظهورها على برنامج الـ 2003 Excel

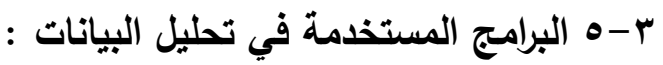

بعد إجراء عملية التصوير الفيدوي تم تحويل الأفلام الفيدويـة إلى أقراص ليزريـة CD. وبعدها تم استخدام البرامج الآتية كل حسب وظيفته للتوصل إلى السلسلة الحركية لفعالية قذف التقل بطريقة أوبراين كما في الملحق ( r )

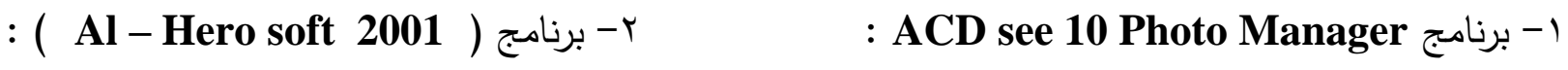

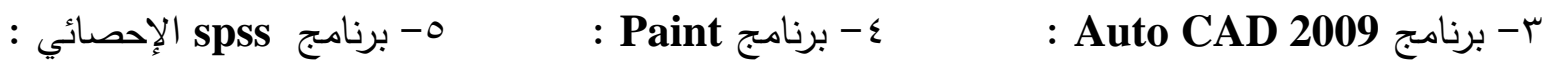

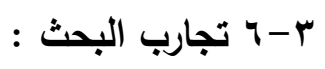
r-

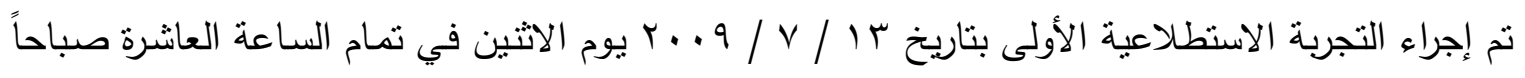
في ملعب جامعـة الموصل على قاذفين اثتين للتقل فئهة المتقدمين مـن منتخب جامعـة الموصل لألعـاب الميدان والمضمار وكان الهدف من إجراء التجربة هو : 1 ا التأكد من صلاحية منصة قوة رد فعل الأرض للعمل في موقعها داخل دائرة القذف . r · وضوح المخططات التي يتم الحصول عليها من تسجيل منصة قوة رد فعل الأرض .

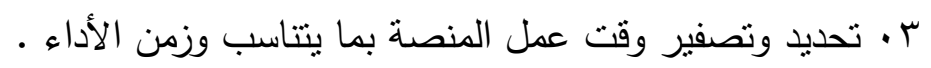
ع · التأكد من موقع منصة قياس قوة رد فعل الأرض داخل دائرة القذف . . ب-

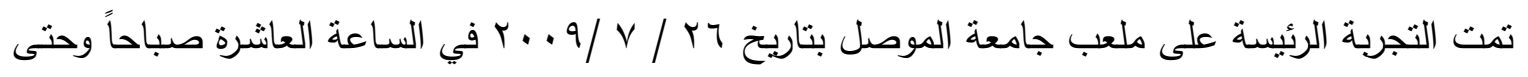
الساعة الثالثة عصراً ، إذ تم الاستفادة من خبرات التجربة الاستطلاعية وإكساب فريق العمل المساعد الدقة في العمل والإجراءات والمعلومات وبما يخدم أهداف البحث ، إذ تم إعطاء كل قاذف ( 7 ) محاولات وتم تحليل أفضلها في الانجاز ( مسافة القذف ) ) 
من خـال اطلاع الباحثنان على عدد من الدراسـات السابقة وتحليل لمحتوى الأدبيات والمقالات والكتب للمتغيرات

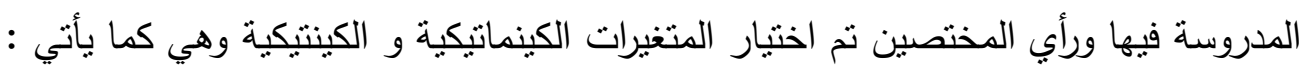

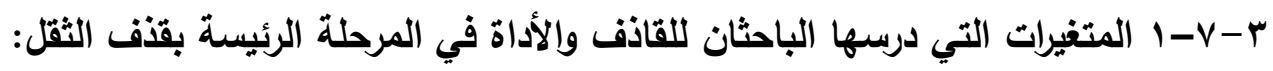

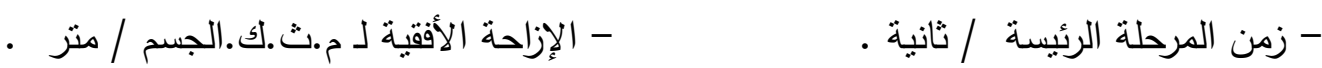

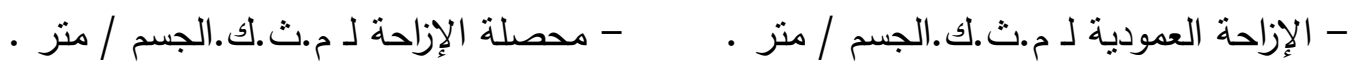

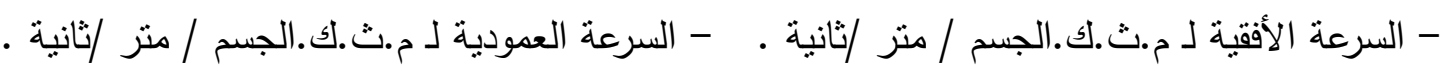

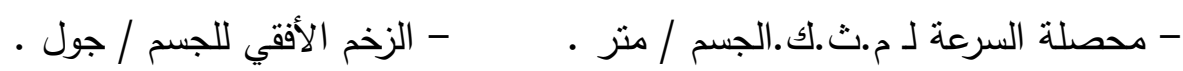

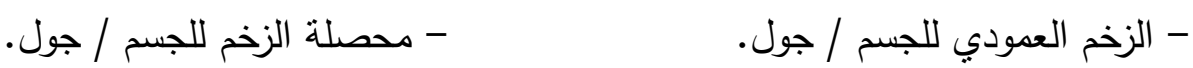

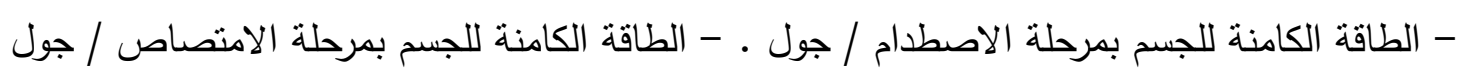

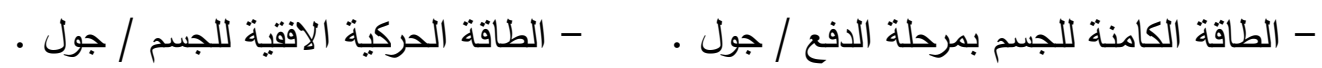

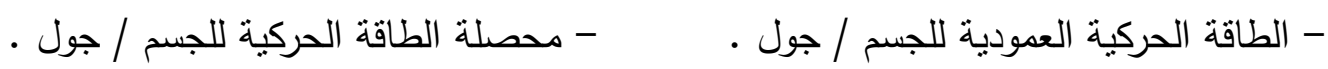

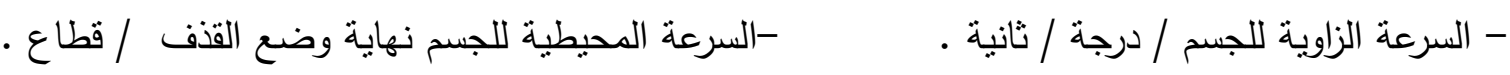

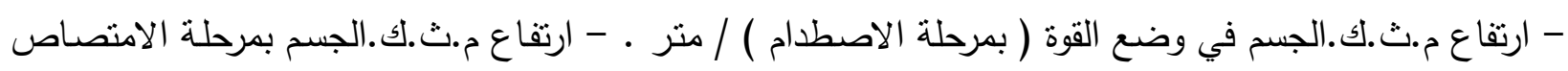

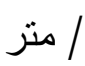
- ارتفاع م.ث.ك.الجسم نهاية وضع القفف ( بمرحلة الدفع ) / متر ـ - الفرق الزاوي للجسم / درجة .

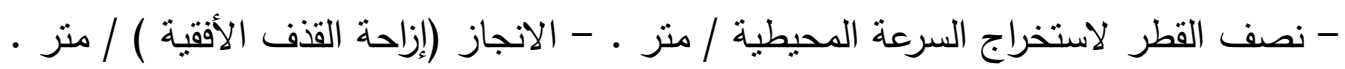

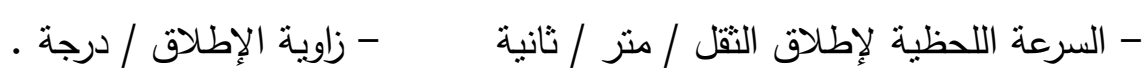

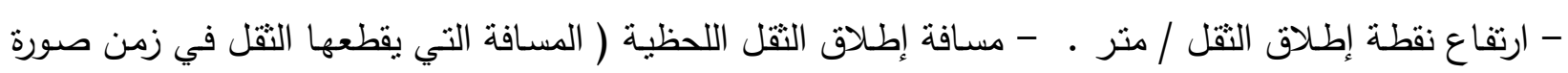

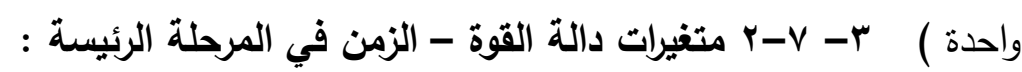

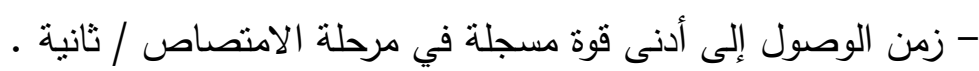

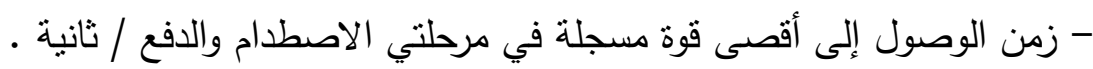

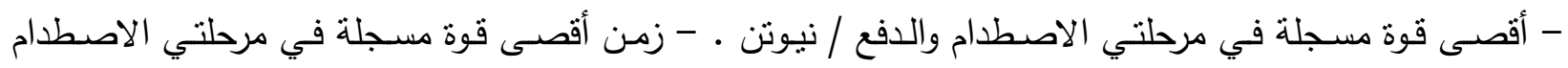

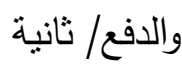

- زمن أدنى قوة مسجلة في مرحلة الامتصاص / ثانية - أدنى قوة مسجلة في مرحلة الامتصاص / نيوتن . - مساحة ما تحت المنحنى / الزمن • / سم / ثانية

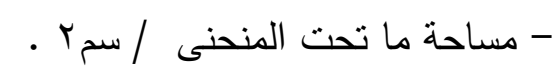

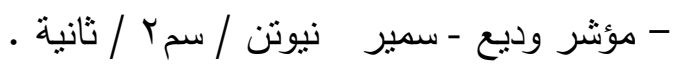


ץ-1-1 - 1-1 بعض المتغيرات الكينماتيكيـة المقاسـة في المرحلـة الرئيسـة بقذف الثقل بطريقة ألزحطقة الخلفيـة

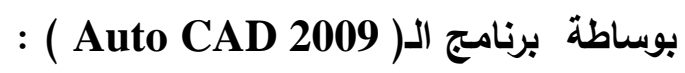
1 ب ارتفاع مركز ثقل كتلة الجسم في وضع القوة : وهو الإزاحة المقاسة من مركز ثقل كتلة القاذف في وضع القوة

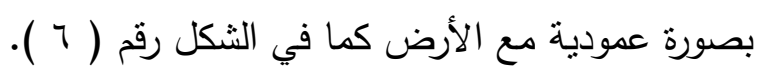
الثكل رقم ( 7 ) يوضح طريقة قياس ارتفاع مركز ثقل كتلة الجسم في وضع القوة والذي يمثل بمرحلة الاصطدام r • أعلى ارتفاع لمركز ثقل كتلة الجسم نهاية مرحلة القذف : وهو المسافة المقاسة من مركز ثقل كتلة القاذف عند

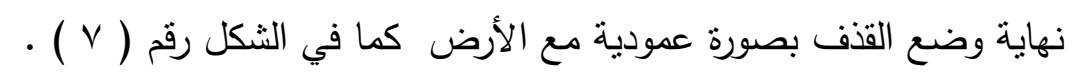

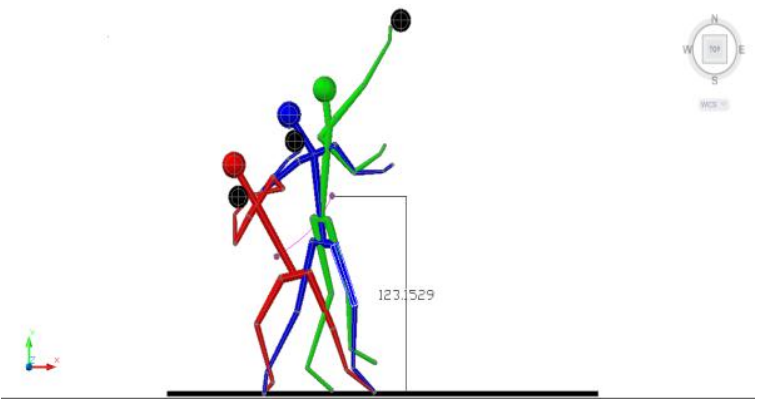

الثكل رقم ( V ) يوضح طريقة قياس أعلى ارتفاع لمركز نقل كتلة الجسم في نهاية وضع القفف في المرحلة الرئيسة r • الفرق الزاوي بين وضع القوة ونهاية مرحلة القذف : وهي الزاوية المحصورة ما بين وضع القوة ووضع القذف فئس

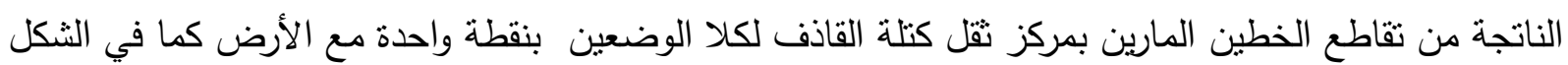

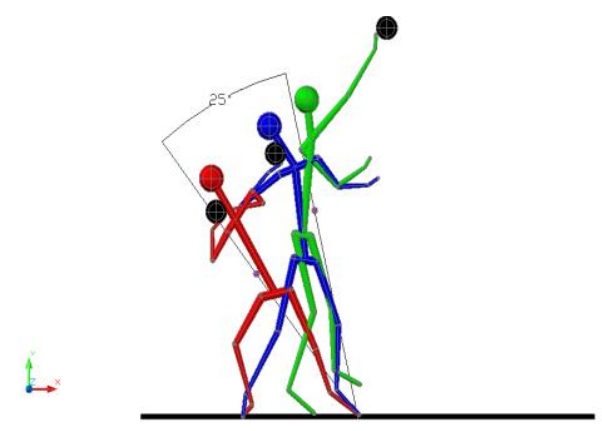

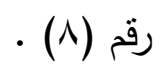

الثكل رقم ( 1 ) يوضح طريقة قياس الفرق الزاوي بين وضع القوة ونهاية مرحلة القذف في المرحلة الرئيسة 
: r-^-r طريقة حساب المتغيرات الكينماتيكية المستخرجة - السرعة الزاوية: احتسب مقدار السرعة الزاوية من خلال استخدام القانون الآتي: التغير الزاوي

السرعة الزاوية = $=\square=\square$ الزمنة

السرعة الزاوية × نصف القطر

) Hall. 1999. 349) سنتيمتر /ثانية $\square \square=$

- السرعة المحيطية -

القطاع

علماً أن الباحثان اعتمد نصف القطر ( نق ) للجسم نهاية لحظة القذف والمتمثل بالخط الواصل بين ( م. ث. ك ج

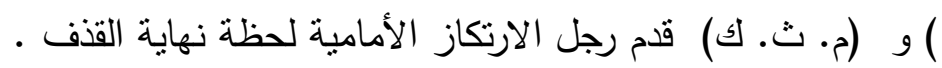
- متغيرات الزمن :- نم قياس المتغيرات الخاصة بالأزمنة استتاداً إلى سرعة آلة التصوير وعدد الصور خلادل الأداء. واحد

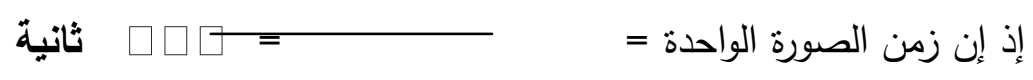

سرعة آلة التصوير

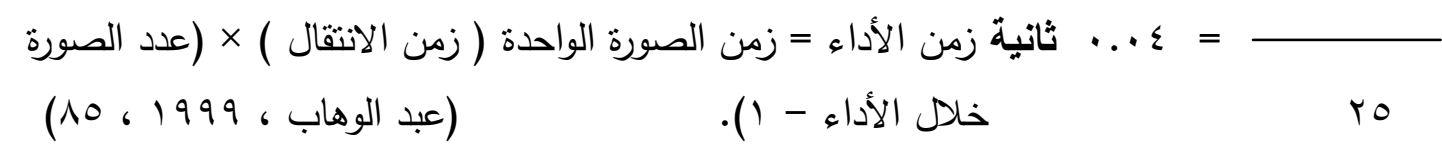

- محصلة الإزاحة للجسم في المرحلة الرئيسـة : - تم استخراج محصلة الإزاحة للجسم في المرحلة الرئيسة من الراء ل

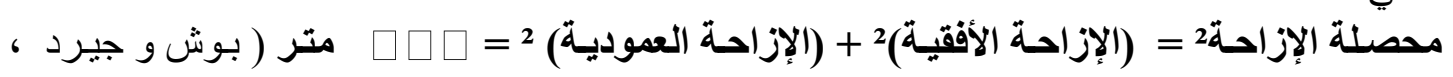

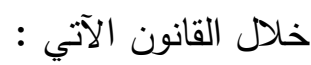

$(1 V-106 r \ldots)$ - محصلة السرعة للجسم بين وضعي القوة والقذف (للمرحلة الرئيسة ): - تم استخر اج محصلة السر عة للجسم بين

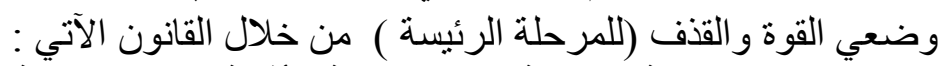

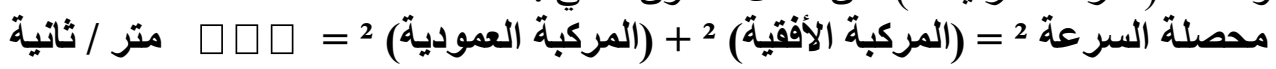

ب-9 الوسائل الإحصائية

استخدم الباحثان الوسائل الإحصائية الآتية : الإيه : الإئية

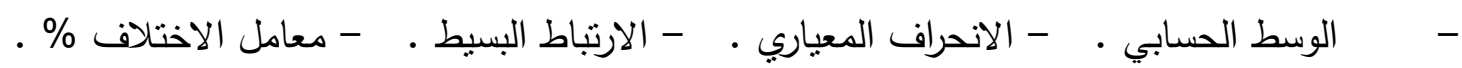

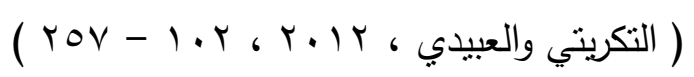

عولجت البيانات إحصائياً باستخدام برنامج (SPSS) إذ نم من خلاله حساب قيم معامل الارتباط البسيط (Person) والمتوسط الحسابي والانحراف المعياري لمتغيرات البحث . 
؛ - 1 - 1 عرض قيم الأوساط الحسابية والانحرافات المعيارية للمتغيرات الكينمايتيكية للمرحلة الرئيسة بقذف الثقل بطريقة الزحلقة لعينة البحث:

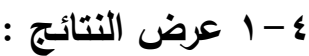

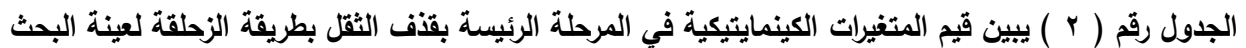

\begin{tabular}{|c|c|c|c|c|c|c|c|c|c|}
\hline نق للجسم & للجسم /درجة الزاوي & لـ محصلة السرعة متك الجسم & 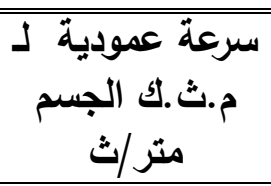 & مرعة أفقية لـ متر الجسم & ألكلية لـ م.ثلة الإزاحة & 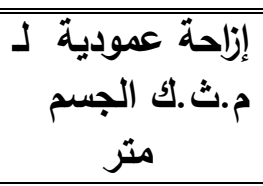 & م. م.ثاحة أفقية لـ الجسم & زمن المرحلة & \\
\hline 99.579 & $r 7$ & 9,911 & $\overline{2} \varepsilon, \wedge \varepsilon 1$ & $\mathrm{V.0VI}$ &. .719 & & $.0 Y Y$ &. .79 & القاذف الأول \\
\hline $1 . V .71 \wedge$ & ro & $\Lambda . \Gamma \leqslant V$ & $0 . \Sigma \Gamma \wedge$ & T.MTY &. .771 & . . & . . $\leqslant \Gamma_{0}$ & 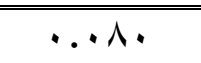 & القاذف الثاني \\
\hline QV.TYA & $r$. & 7.รᄉ। & 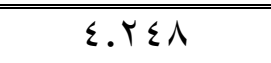 & $\varepsilon . \wedge 90$ & . . $\leqslant \vee q$ & . . II & & ..V V & القاذف الثالث \\
\hline 117.71 & rI & $7.7 V$. & S.YY & 0.174 & $.0 \mathrm{NV}$ &..$M V Y$ & . . $\leqslant 0 \leqslant$ & $\because \cdots \wedge \wedge$ & القاذف الرابع \\
\hline 1.0 .104 & $r r$ & V.Tr. & 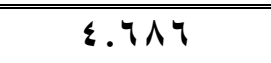 & 0.99 &. $.0 \wedge \wedge$ & Eצ & $\cdot . \varepsilon \leqslant \psi$ & $\ldots \vee \wedge$ & س- \\
\hline$\overline{~ A . V V Y}$ & r. $9 \leq \leq$ & I.YMY & $.0 \mathrm{VO}$ & I.YYO & $\ldots \wedge$. & ...Or &. .97 & $\ldots 1$ & $\varepsilon^{ \pm}$ \\
\hline
\end{tabular}

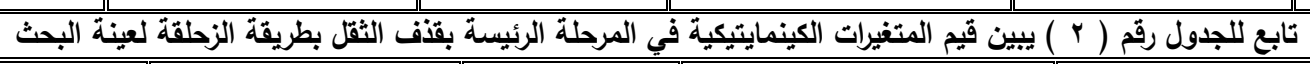

\begin{tabular}{|c|c|c|c|c|c|c|c|c|}
\hline الانجاز /متر & إطلاق الثقل / إتقاع نقطة & سترعة إطلاق الثلة & مسافة إطلاق الثقل & الثقلة/درجة إطلاق & الجسم بوضع م. القذف & الإتفاع م.ث.ك. & بوضع القوة /متر م.ثر & \\
\hline $1 Y .9$. & $1 . \wedge \wedge r$ & IT.VAO & .011 & $\varepsilon 7$ & 1.997 & $.9 \vee 7$ &.$\wedge V T$ & القاذف الأول \\
\hline 11.74 & $r . . \wedge 7$ & A.rTo & . & ro & 1.114 & $1 .+r \varepsilon$ & $.9 r r$ & القاذف الثاني \\
\hline $11 . \varepsilon r$ & 1.170 & $1 . .749$ & . EYT & $\sum \Lambda$ & $1 . . \leqslant 9$ & .971 &. .179 & القاذف الثالث \\
\hline $1 Y . \leqslant 7$ & 5.171 & $1 \cdot . \leqslant 1 Y$ &..$\Sigma 1 V$ & rᄉ & $1 . r 09$ & $1 . . v r$ &. .991 & القاذف الرايع \\
\hline $1 Y .1 \cdot r$ & 1.999 & $1 \cdot .0 \leqslant r$ &..$\varepsilon r r$ & $\varepsilon 1.10$ & $1.1 \leq 71$ & $1 . .11$ & .9100 & س- \\
\hline. .797 & $.1 \leq \Lambda$ & 1.119 &..$V T$ & 7. YTA &. .94 &. $.0 \%$ &. .7 . & $\varepsilon^{ \pm}$ \\
\hline
\end{tabular}


ع - 1-r عرض قيم الأوساط الحسابية والانحرافات المعيارية للمتغيرات الكينتيكية في المرحلة الرئيسة بقذف الثقل بطريقة الزحلقة لعينة البحث:

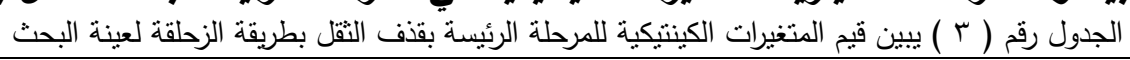

\begin{tabular}{|c|c|c|c|c|c|c|c|c|c|}
\hline الكلي للجسمة الزخم & للجسم / الزودي & للجسم / الزخم / الأفقي & الحركية الكلية للجسم الطاقة & كية العمودية الحر & كية ألأفقية الحر & اللجسم بوضع الكامنة & الطاقة الكامنة للجسم الامتصاص & للجسم بوضع القوة & \\
\hline 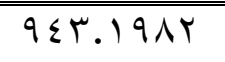 & $0 . V .0 \wedge r$ & V9ะ.977 & $r r \leqslant 9 . \wedge 0 V$ & IYYT.AOV & r....r人o & IIYq.YAr & $1 \ldots 0 .+Y \varepsilon$ & ᄉ99.7rᄉ & مظفر عصمت \\
\hline Vqr.qro & $017.09 \varepsilon$ & 7.1 .079 & Trד & $1 \leq . \leq .0 \vee 0$ & $19 . \varepsilon .71 \leq$ & $11 \cdot Y . V \leq V$ & $97 r .0 . V$ & $109 . V \cdot r$ & صهيب محمد \\
\hline OOV.rAs & r. & $\varepsilon r \cdot .90 V$ & $1 Y \wedge 9 . \wedge 1$. & VVI... & $1 . r \cdot . r 09$ & $1 \wedge \varepsilon .911$ & N1..vrq & VTr.TIs & احمد الحاصود \\
\hline VVT.VTO & $\varepsilon q \ldots .+1$ & $09 \Lambda . \wedge Y 1$ & $117 . .1 \vee 7$ & $1 . r 0 . . T \leq$ & $10 \leq 0.7 \mu$ & $1 \leqslant r r . r \cdot q$ & $M r \cdot . V \cdot q$ & 1114.741 & عمر يوسف \\
\hline VI .AYI & $\leqslant 79.110$ & $7 . \varepsilon . . V V$ & $1191.0 \wedge 9$ & $111 \cdot .71 \leq$ & IAVY.\&VY & $11 \mathrm{rv} .074$ & 999.990 & $9 \cdot V . r 19$ & س- \\
\hline $10 \wedge . \wedge 0 \mu$ & $V . .077$ & lor.V09 & ATI.rVA & FqG.rYT & $\wedge$ А. ... & YYO.OYI & $179 . r . r$ & $171.0 \cdot V$ & $\varepsilon^{ \pm}$ \\
\hline
\end{tabular}

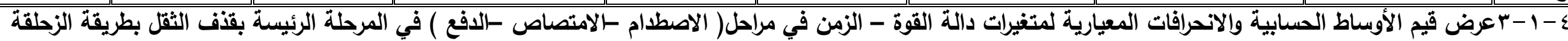

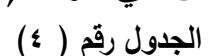

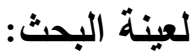

يبين قيم متغيرات دالة القوة -الزمن في مرحلة الاصطدام لعينة البحث

\begin{tabular}{|c|c|c|c|c|c|c|c|c|c|}
\hline زمن الاصطام & 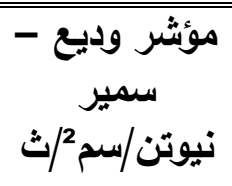 & المنحنى / الزمن سمّاحة ما تحت & تحت المنحنى مساحة ما & 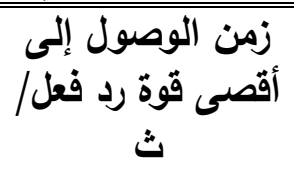 & قوة رد فعل أقصى & فقعل/ نيوتن قوة رد & نظام الوزن & & $ت$ \\
\hline. .11. & 8.979 & $|\Pi \wedge.| \wedge \mid$ & $10 . Y$ & $\ldots v$. & $\ldots 1 \ldots$ & rorA & $11 \cdot 1 . Y V 1$ & مظفر عصدت & 1 \\
\hline .010 & 1.00 & IV.ru & $1 V .7$ & .11 . & $.1 \leq$. & $r \leqslant r$. & 1.r.|V1 & صهيب محمد & $r$ \\
\hline. $.1 \%$. & 0.001 & 175.710 & YI.s & $\ldots 9$. &. $.1 Y$. & Tos. & $91 \leq . \wedge \wedge 1$ & احمد الحاصود & $r$ \\
\hline .ro. & $\Lambda . \wedge / T$ & ITV.r & $r \varepsilon . r$ & $\cdot r l$. & $\because r \leq$. & 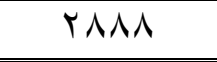 & $1 Y .9 .111$ & عمر يوسف & $\varepsilon$ \\
\hline .19. & V.VYr & Irq.rrr & YY.IYO & $.1 Y$. & .10 & 97.7 .0 & $1.0 \mathrm{~V} .1 \mathrm{YT}$ & س- & \\
\hline$\ldots 7 r$ & $1 . \leqslant \wedge 7$ & 19.599 & 1.0 .9 & $\cdots 7 r$ & $\ldots 9 r$ & 197.194 & Irq.VVr & $\varepsilon \pm$ & \\
\hline
\end{tabular}


الجدول رقم ( • ) يبين قيم متغيرات دالة القوة -الزمن في مرحلة الامتصاص لعينة البحث

\begin{tabular}{|c|c|c|c|c|c|c|c|c|c|}
\hline زمن الامتصاص ث & سئشير & 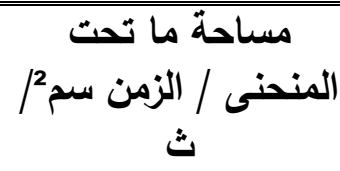 & المنحنَ/ مساحة سم² & زأنى قوة الوصول إلى فعل / & زمن أدنى قوة & فعل أدنى قوة رد & نظيو الوزن & المت & ت \\
\hline . & 1.017 & $\mid$ |YA.YYI & r9.0 & ... $\varepsilon$. & . $r \varepsilon$. & $0 \leqslant$. & $11 \cdot 1 . Y V 1$ & مظفر عصمت & 1 \\
\hline ..YI. & A..1. & ITO.YKA & TY.r & ... & . & 707 & $1 \ldots r . \mid V 1$ & صهيب محمد & r r \\
\hline ב.rT. & $0.91 Y$ & loక.VAT & T0.7 & ... & . & 1119 & $91 \leq . \wedge \wedge 1$ & احمد الحاصود & r \\
\hline$\ldots 9$. & A.|YI & $1 \leqslant \wedge . \wedge \wedge q$ & $1 \% . \Sigma$ & $\ldots r$. & . $r \varepsilon$. & DTr & $\mid r .9 .111$ & عمر يوسف & $\varepsilon$ \\
\hline. .19. & $\mathrm{~V} .70 \mathrm{~V}$ & Irq.rqr & YY.Y &..$r 0$. &.$\mu_{0}$. & $V \cdot \varepsilon .0$ & $1.0 V .1 Y 7$ & س- & \\
\hline$\ldots 7 V$ & 1.119 & $1 \leq . V T \varepsilon$ & 9.1790 & $\ldots 1$. &. $.1 r$ & $1 \leq 7 . \% 71$ & IYq.VVr & $\varepsilon \pm$ & \\
\hline
\end{tabular}

الجدول رقم ( ا ب ) يبين قيم متغيرات دالة القوة -الزمن في مرحطة الدفع لعينة البحث

\begin{tabular}{|c|c|c|c|c|c|c|c|c|c|}
\hline زمن الافع & 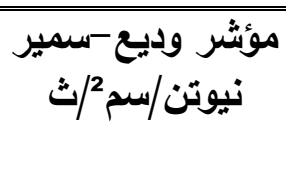 & المنحنى / الزمن سمة مساحة & تعت المنحنى مساحة ما & أقصى قوة الوصول إلى فعل/ & زمن فُ فقصل قوة & فعل/ فئصى قوة رد & نظام الوزن & اله & | \\
\hline . & A.Vry & 1 1Y..71 & \&1.7 & $\ldots \varepsilon$. & $\therefore \leqslant 0$. & $\Gamma \cdot \Sigma \Lambda$ & $11.1 . Y V 1$ & مظفر عصمت & 1 \\
\hline . . SY. & 9.915 & 1.1 .191 & $\leqslant Y .0$ & $\ldots \varepsilon$. &..$\leqslant \wedge$. & ITH & $1 . . r .|V|$ & صهيب محمد & T \\
\hline . & А... & $11 \leqslant . Y \leqslant Y$ & $\varepsilon V .7$ & $\ldots \varepsilon$. & $.0 Y$. & Tos. & $9) \leq . \wedge \wedge 1$ & احمد الحاصود & $r$ \\
\hline. $.0 Y$. & $\varepsilon . \varepsilon q Y$ & r79.r & TV.r & $\ldots \leqslant$. & ..7Y. & TVVT & $1 Y .9 .111$ & عمر يوسف & $\varepsilon$ \\
\hline..$\varepsilon \cdot r$ & $\vee . \vee \wedge \wedge$ & 10Y.7VE & $\leqslant 9.10$ & $\ldots$ &. .011 & $Y q V \cdot .0$ & $1.0 V .1 Y 7$ & س- & \\
\hline$\ldots 91$ & Y.rTT & $\vee \wedge . \Psi \leq \nearrow$ & 11.990 & $\cdots \cdots$ & $\ldots v \varepsilon$ & MIr..人q & IYY.VVT & $\varepsilon \pm$ & \\
\hline
\end{tabular}


؛

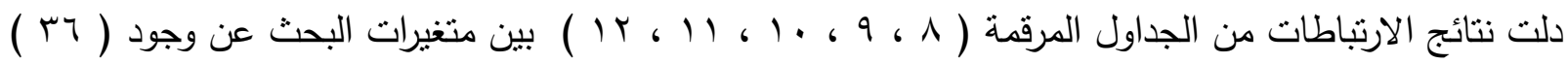
ارتباطاً معنوياً منها ( اب ) ارتباطاً معنوباً موجباً و (

إلى أن كثرة عدد المتغيرات في مصفوفة الارتباطات دعت الباحثان إلى ذكر الارتباطات المعنوية فقط وكما يأتي : ع - ب - الارتباطات المعنوية بين المتغيرات الكينماتيكية في المرحلة الرئيسة بقذف الثقل بطريقة الزحلقة لعينة البحث :

جدول رقم (^)

* يبين الارتباطات المعنوية بين المتغيرات الكينماتيكية في المرحلة الرئيسة بقذف الثقل بطريقة الزحلقة العينة البحث

\begin{tabular}{|c|c|c|c|}
\hline الاحتمالية & قليمة ( ر ) & الارتباطات المعنوية & ت \\
\hline$\cdot, r$ r & $\cdot, 9 \vee V$ & السرعة الأفقية لـ م.ث.ك الجسم × محصلة السرعة للجسم & -1 \\
\hline$\cdot, \cdot \varepsilon r$ & $\cdot, 90 \wedge$ & السرعة الأفقية لـ م.ث.ك الجسم × الفرق الزاوي للجسم & $-r$ \\
\hline$\cdot, \cdots$ & $\cdot, 990$ & محصلة السرعة الكلية للجسم × الفرق الزاوي للجسم & -4 \\
\hline$\cdot, \cdots$ & $1, \cdots$ & مسافة إطلاق التقل اللحظية × سرعة إطلاق النقل اللحظية & $-\varepsilon$ \\
\hline$\cdot, \cdot r r$ & $\cdot, 9 \vee \wedge$ & ارتفاع م.ث.ك الجسم نهاية وضع القذف × ارتفاع نقطة إطلاق التقل & -0 \\
\hline ס ., & $\cdot, 970$ & القذفاع م.ث.ك الجسم في وضع القوة × ارتفاع م.ث.ك الجسم في نهاية وضع & -7 \\
\hline$\cdot, \cdot r \cdot$ & $\cdot, 9 \vee \cdot$ & ارتفاع م.ث.ك الجسم في وضع القوة × ارتفاع م.ث.ك الجسم في وضع الامتصاص & $-V$ \\
\hline
\end{tabular}

من الجدول رقم ( ^ ) يتبين ما يأتي :

ا- الارتباط المعنوي الموجب بين السرعة الأفقية لـ م.ث.ك الجسم ومحصلة السرعة في المرحلة الرئيسة بقذف الثقل بطريقة أوبراين يعزوه الباحثان إلى ان محصلة السرعة تعتمد على متغيرين في زيادتها أو نقصانها إذ تنص معادلة محصلة السرعة على : الس

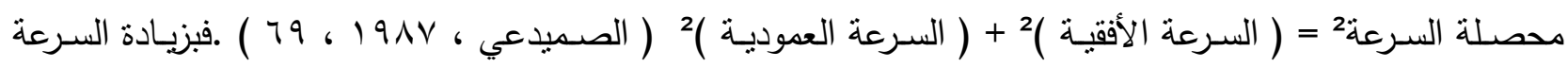

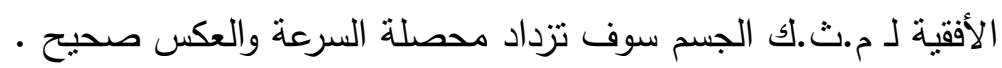
ب- الارتباط المعنوي الموجب بين السرعة الأفقية لـ م.ث.ك الجسم والفرق الزاوي للجسم في المرحلـة الرئيسة بقذف التقل بطريقة أوبراين يعزوه الباحثان إلى إن الفرق الزاوي للجسم هو مقدار الزاوية المتكون بين وضعين أو أكثر وبما أن المرحلة الرئيسة بقذف الثقل بطريقة أوبراين تمر بثلاث مراحل هي ( الاصطدام ، والامتصـاص ، والدفع ) وللتغلب على هذا الفرق في الزاوية كان لابد من زيادة السرعة الأفقية ، فكلما زاد الفرق الزاوي زادت معه الإزاحة الأفقية للجسم التي هي بسط معادلة السرعة الأفقية كما ورد ذلك في ارتباط معنوي سابق ، لذلك كلما زاد الفرق الزاوي زادت معه

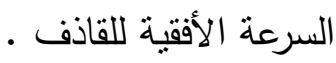
r- الارتباط المعنوي الموجب بين محصلة السرعة والفرق الزاوي للجسم يعزوه الباحثان إلى ان زيادة الفرق الزاوي معناه قطع الجسم زاويـة كبيرة تؤدي إلى زيادة الازاحتين الأفقية والعموديـة ، فكلما زادت إحدى الازاحتين أو كلاهما زادت 


\section{دراسة تمليلية لعدد من المتغيرات البايوميكانيكية في المرملة الرنيسة بقذف...........}

المحصلة ومحصلة السرعة تعتمد في قيمها على المركبة الأفقية لـ م.ث.ك الجسم والمركبة العمودية لـ م.ث.ثك الجسم

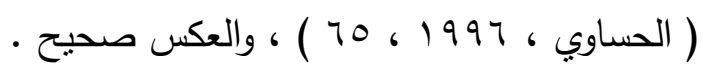
ع-الارتباط المعنوي الموجب بين مسافة إطلاق الثقل اللحظية وسرعة إطلاق الثقل اللحظية يعزوه الباحثان إلى ان سرعة الإطـلاق اللحظية تعتمد على مسافة الإطلاق اللحظية والزمن ، فبزيادة مسافة التقل تزداد السرعة في وحدة زمنية ثابتة حسب معادلة السرعة :

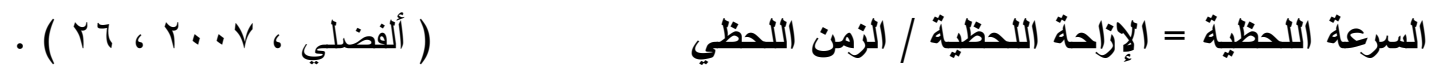

ه- الارتباط المعنوي الموجب بين ارتفاع م.ث.ك الجسم نهاية وضع القذف وارتفاع نقطة إطلاق النقل يعزوه الباحثان إلى انه كلما كان هناك ارتفاع في م.ث.ك الجسم نهاية وضع القذف كان مقابله ارتفاع في نقطة إطلاق الثقل وتامين احد شروط تحقيق الانجاز في هذه الفعالية ، وهذا يؤدي إلى ارتفاع الجسم كون أن نقطة انطلاق النقل تعتمد على امتداد الجسم وطول الذراع وزاوية الإطلاق ( الطالب ، 1911 ، 190 ( ) ) . צ- الارتباط المعنوي الموجب بين ارتفاع م.ث.ك الجسم بوضع القوة وارتفاع م.ث.ك الجسم نهاية وضع القذف في المرحلة الرئيسة بقذف التقل بطريقة أوبراين يعزوه الباحثان إلى متطلبات الأداء الفني السليم ، فعندما يصل القاذف إلى وضع القع القوة كان من الضروري المحافظة على ارتفاع م.ث.ك جسمه ليتهيأ من خلال مرحلة الامتصاص إلى رفع م.ث.ك الك

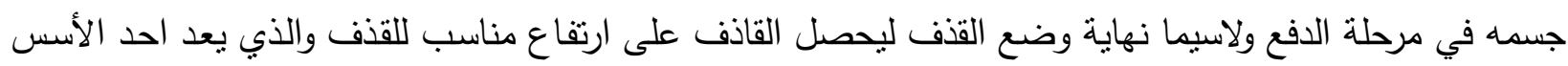

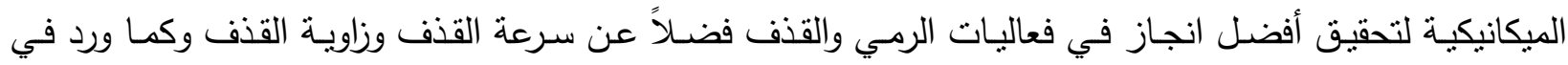

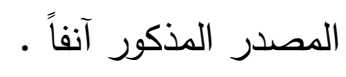
V- الارتباط المعنوي الموجب بين ارتفاع م.ث.ك الجسم بوضع القوة وارتفاع م.ث.ك الجسم بوضـع الامتصاص في المرحلة الرئيسـة بقذف التقل بطريقة أوبراين يعزوه الباحثنان إلى انه كلما كان هنالك ارتفاع في م.ث.ك الجسم بوضـع القوة سوف يعقبه ارتفاع في م.ث.ك الجسم بوضـع الامتصـاص وحسب التسلسـل الحركي للمرحلـة الرئيسـة بقذف النقل

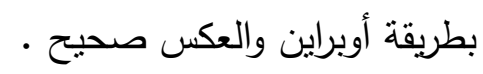

ع - Y - r الارتباطات المعنوية بين المتفيرات الكينتيكية في المرحلة الرئيسة بقذف الثقل بطريقة الزحلقة لعينة البحث : جدول رقم ( 9 )

يبين الارتباطات المعنوية بين المتغيرات الكينتيكية في المرحلة الرئيسة بقفف الثقل بطريقة الزحلقة لعينة البحث

\begin{tabular}{|c|c|c|c|}
\hline 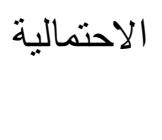 & قيمة ( ر ) & 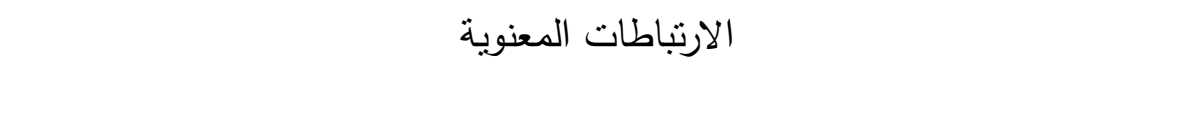 & ت \\
\hline$\cdot, \cdot 1 \mathrm{r}$ & $\cdot, 9 \wedge \wedge$ & الزخم الأفقي للجسم × محصلة الزخم الكلي للجسم & -1 \\
\hline$\cdot, \cdot r \cdot$ & $\cdot, 9 \vee \cdot$ & الزخم الأفقي للجسم × الطاقة الحركية الأفقية للجسم & $-r$ \\
\hline 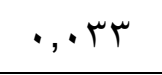 & $\cdot, 97 \mathrm{~V}$ & الزخم الأفقي للجسم × محصلة الطاقة الحركية الكلية للجسم & r \\
\hline$\cdot, \cdot \leq 7$ & $\cdot, 90 \leqslant$ & محصلة الزخم الكلي للجسم × محصلة الطاقة الحركية الكلية للجسم & $-\varepsilon$ \\
\hline$\cdot, \cdots v$ & $\cdot, 994$ & الطاقة الحركية الأفقية للجسم × محصلة الطاقة الحركية الكلية للجسم & -0 \\
\hline$\cdot, \cdots$ & $\cdot, 999$ & الطاقة الكامنة للجسم بوضع الامتصاص × الطاقة الكامنة للجسم نهاية وضع القذف & -1 \\
\hline
\end{tabular}




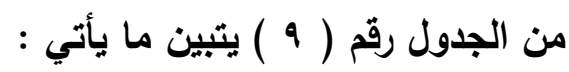

1- الارتباط المعنوي الموجب بين الزخم الأفقي للجسم ومحصلة الزخم الكلي للمرحلة الرئيسة بقذف النقل بطريقة

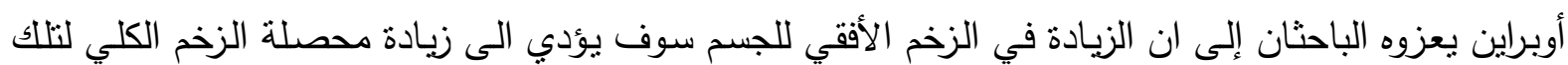

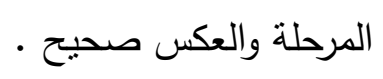

ז- الارتباط المعنوي الموجب بين الزخم الأفقي للجسم والطاقة الحركية الأفقية بعزوه الباحثان إلى ان كلا المتغيرين

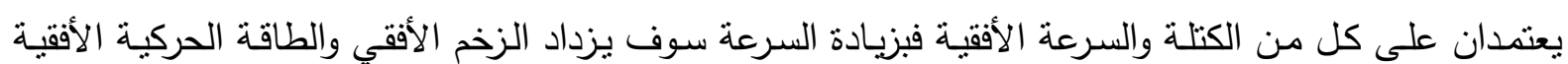

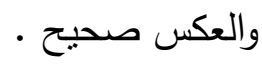

r- الارتباط المعنوي الموجب بين الزخم الأفقي للجسم ومحصلة الطاقة الحركية يعزوه الباحثان إلى السبب عينه في

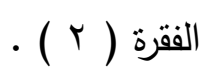

ع- الارتباط المعنوي الموجب بين محصلة الزخم الكلي للجسم ومحصلة الطاقة الحركية للجسم يعزوه الباحثان إلى أن

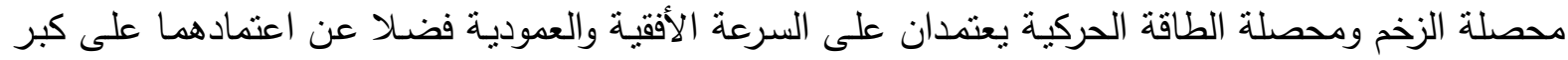
وحجم كتلة القاذف فبزيادة هذه المتغيرات الكينمانيكية ستزيد بذلك محصلة الزخم الكلي ومحصلة الطاقة الحركية

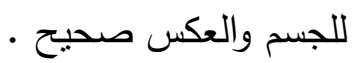

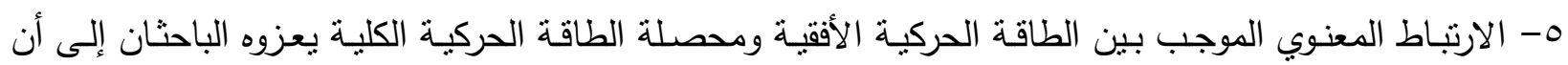

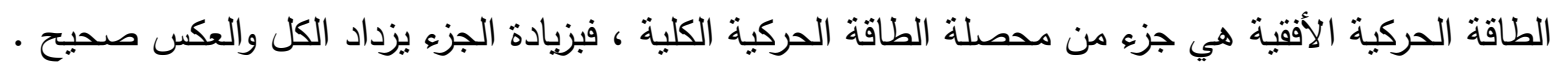

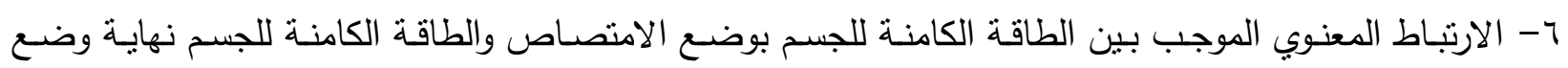

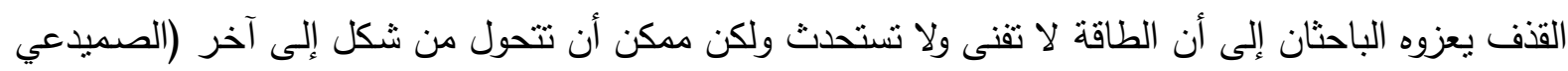
،

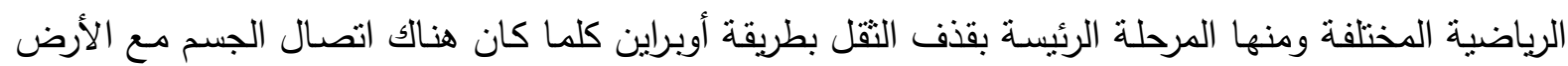

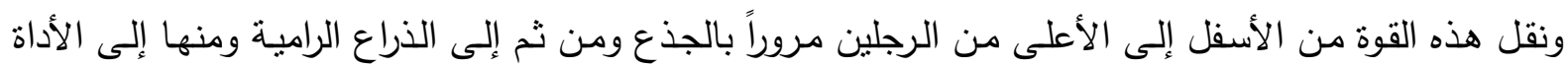

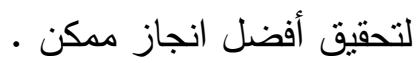

؟ - -r الارتباطات المعنوية بين المتغيرات الكينماتيكية والكينتيكية في المرحلة الرئيسة بقذف الثقل بطريقة

\begin{tabular}{|c|c|c|c|}
\hline 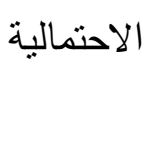 & قليمة ( ر ) & 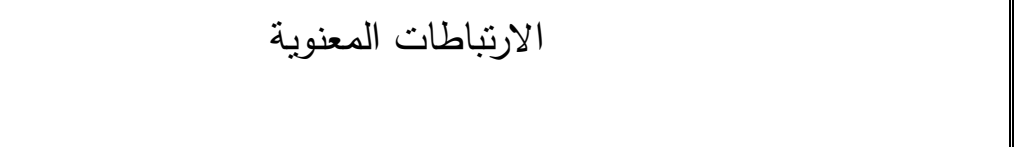 & $ت$ \\
\hline$\cdots 99$ & .911 & || الإزاحة الأفقية لـ م.ث.ك الجسم × محصلة الزخم للجسم & -1 \\
\hline$\cdot, \cdot \varepsilon \cdot$ & $\cdot, 97$. & || محصلة الإزاحة الكلية للجسم× الزخم العمودي للجسم & $-r$ \\
\hline$\cdot, .17$ & $\cdot, 9 \wedge \varepsilon$ & | محصلة الإزاحة الكلية للجسم × الطاقة الحركية العمودية للجسم & $-r$ \\
\hline$\cdot, \cdot, r 4$ & $\cdot, 9 \vee \leqslant$ & || السرعة الأفقية لم.ث.ك الجسم × الطاقة الحركية الأفقية للجسم & $-\varepsilon$ \\
\hline$\cdot, \cdot r \cdot$ & $\cdot, 9 \Lambda$. & || السرعة الأفقية لم.ث.ك الجسم × محصلة الطاقة الحركية الكلية للجسم & -0 \\
\hline$\cdot, \cdot, 9$ & $\cdot, 991$ & || الإزاحة الأفقية لـ م.ث.ك الجسم × الزخم الأفقي للجسم & -7 \\
\hline
\end{tabular}

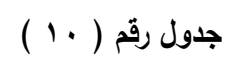

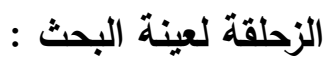

يبين الارتباطات المعنوية بين المتغيرات الكينماتيكية والكينتيكية في المرحلة الرئيسة بقذف الثقل بطريقة الزحلقة لعينة البحث 


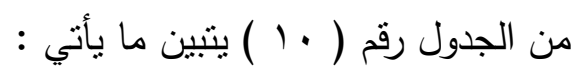

1- الارتباط المعنوي الموجب بين الإزاحة الأفقية لم.ث.ك الجسم ومحصلة الزخم الكلي في المرحلة الرئيسة لقذف النقل

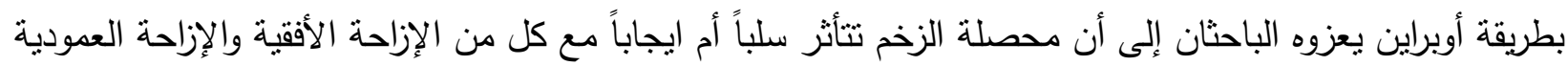

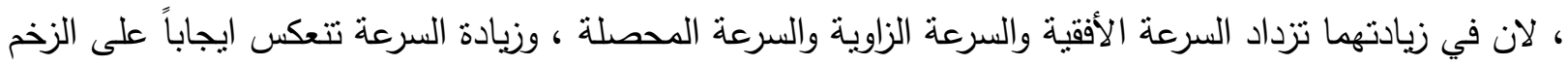

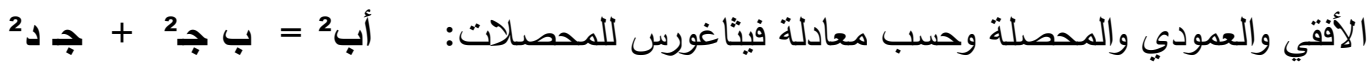

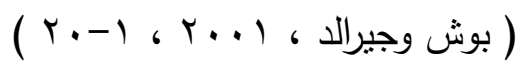

r- الارتباط المعنوي الموجب بين محصلة الإزاحة للجسم والزخم العمودي للجسم يعزوه الباحثان إلى أن الأخير يعتمد في التي

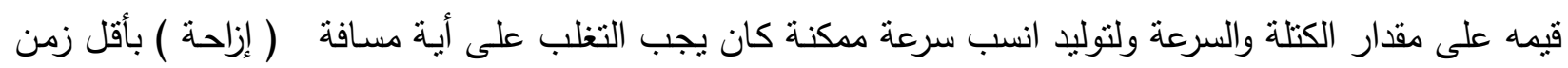

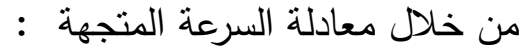

السرعة المتجهة = مركبة الإزاحة الأفقية / الزمن

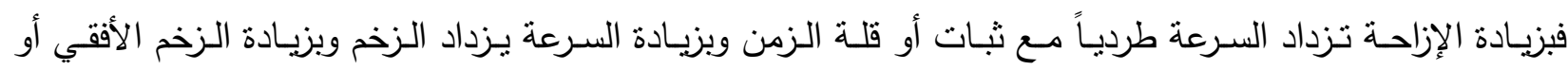

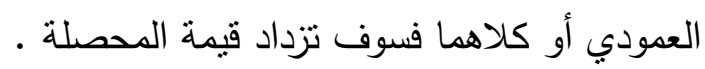
ب- الارتباط المعنوي الموجب بين محصلة الإزاحة الكلية والطاقة الحركية العمودية يعزوه الباحثان إلى كون الطاقة الحركية

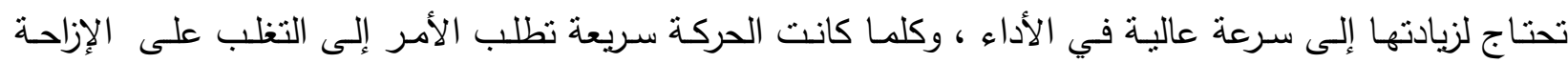

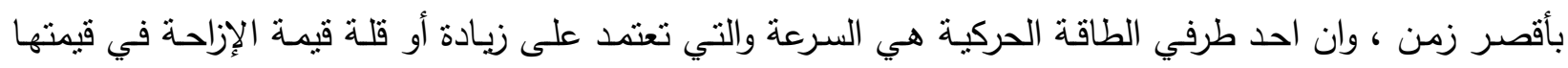

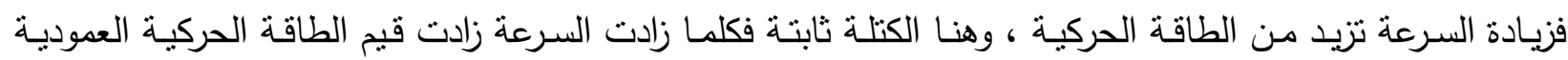

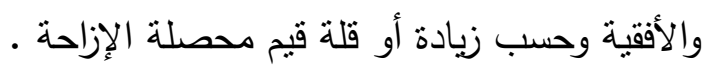

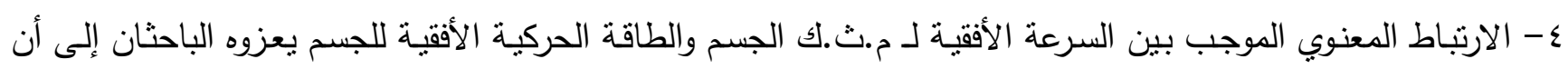

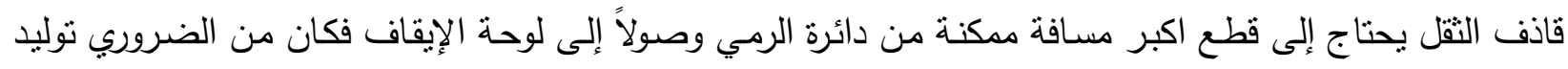

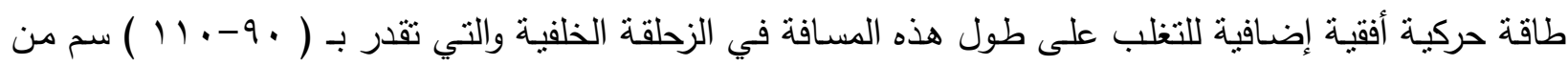

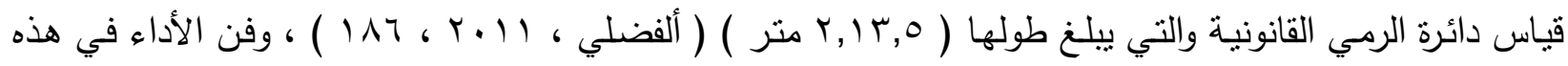

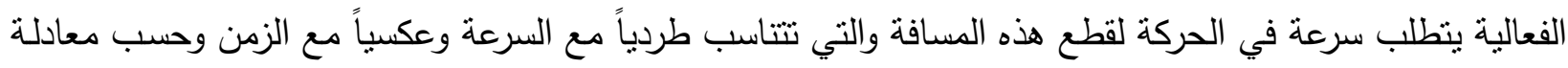

$$
\text { السرعة : }
$$

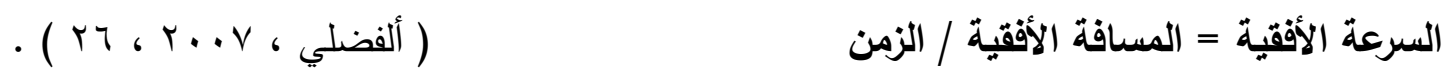

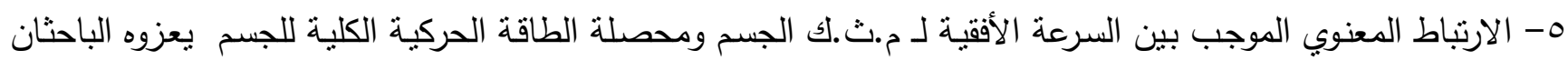

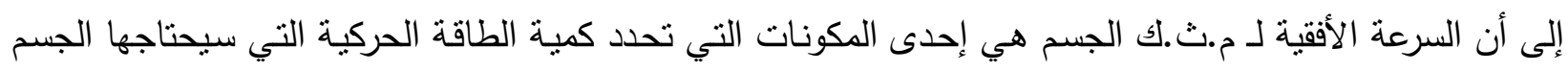

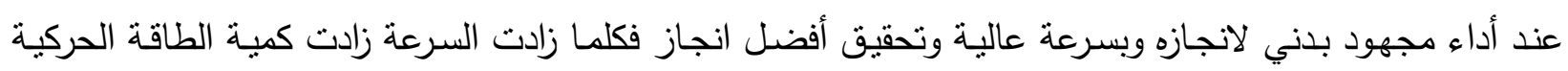

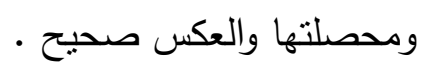

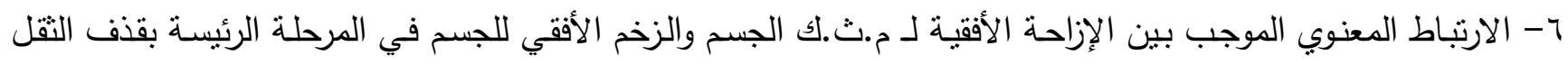

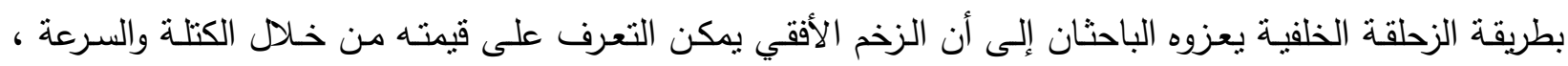

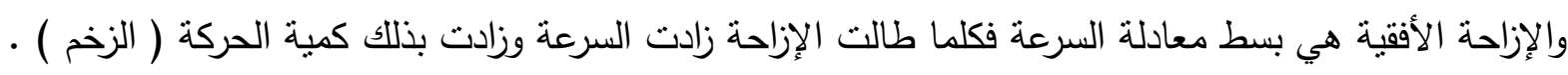


ـ - ץ- ـ الارتباطات المعنوية بين متغيرات دالة القوة - الزمن في المرحلة الرئيسة بقذف الثقل بطريقة الزحلقة لعينة

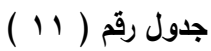

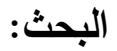

يبين الارتباطات المعوية بين متغيرات دالة القوة - الزمن في المرحلة الرئيسة بقنف الثقل بطريقة الزحلقة لعينة البحث

\begin{tabular}{|c|c|c|c|}
\hline |الاحتمالية & قيمة (ر المسوية ) & 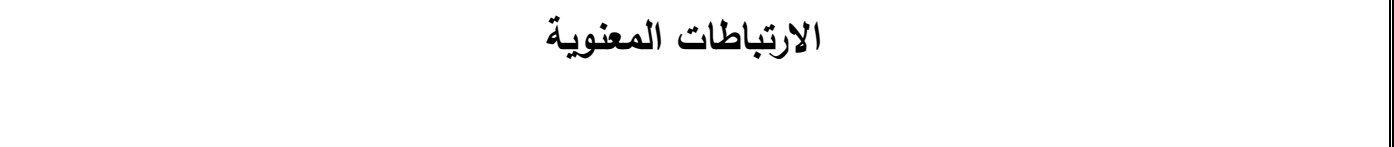 & ت \\
\hline$\cdots \leqslant 9$ & $\cdot, 901$ & زمن أقصى قوة رد فعل في مرحلة الاصطدام × مساحة ما تحت المنحنى في مرحلة الاصطدام & -1 \\
\hline$\cdot, \cdot \leq q$ & $\cdot, 901$ & زالاصطدام الوصول إلى أقصى قوة رد فعل في مرحلة الاصطدام× مساحة ما تحت المنحنى في مرحلة & $-Y$ \\
\hline$\cdot, \ldots$ & $1, \ldots$ & زالاصطدام أقصى قوة رد فعل في مرحلة الاصطدام × زمن الوصول إلى أقصى قوة رد فعل في مرحلة & r \\
\hline$\cdot, \cdots$ & $1, \cdots$ & زمن الوصول إلى أقصى قوة رد فعل في مرحلة الاصطدام × زمن الاصطدام & $-\varepsilon$ \\
\hline$\cdot, \cdot \leq 9$ & $\cdot, 901$ & |مساحة ما تحت المنحنى/ الزمن في مرحلة الاصطدام × زمن الاصطدام & -0 \\
\hline$\cdot, \cdot \leq \uparrow$ & $\cdot, 90 \leqslant-$ & زمن الامتصاص × مساحة ما تحت المنحنى في مرحلة الدفع & -7 \\
\hline$\cdot, \cdot r \varepsilon$ & $\cdot, 977-$ & زمن الامتصاص × مساحة ما تحت المنحنى/الزمن في مرحلة الدفع & $-V$ \\
\hline$\cdot, \cdot \leq \wedge$ & $\cdot, 90 \mathrm{r}$ & مساحة ما تحت المنحنى في مرحلة الامتصاص × زمن الدفع & $-\Lambda$ \\
\hline$\cdot, \cdot 19$ & $\cdot, 9 \wedge 1$ & زمن أقصى قوة رد فعل في مرحلة الدفع × مساحة ما تحت المنحنى في مرحلة الدفع & -9 \\
\hline$\cdot, \cdot r \cdot$ & $\cdot, 9 \vee \cdot$ & زمن الوصول إلى أقصى قوة رد فعل في مرحلة الدفع × مساحة ما تحت المنحنى في مرحلة الدفع & -1 \\
\hline$\cdot, \cdot r_{4}$ & $\cdot, 97 \varepsilon$ & مساحة ما تحت المنحنى في مرحلة الدفع × مساحة ما تحت المنحنى/الزمن في مرحلة الدفع & -11 \\
\hline$\cdot, \cdot r \cdot$ & $\cdot, 9 \vee$. & زمن مرحلة الدفع × مؤشر وديع سمير في مرحلة الدفع & -14 \\
\hline$\cdot, \cdot 4$ & $\cdot, 971$ & |مساحة ما تحت المنحنى/الزمن في مرحلة الدفع × مؤشر وديع سمير في مرحلة الدفع & $-1 T$ \\
\hline$\cdot, \cdots 1$ & $\cdot, 999$ & زمن الوصول إلى أقصى قوة رد فعل في مرحلة الدفع × زمن أقصى قوة رد فعل في مرحلة الدفع & $-1 \leqslant$ \\
\hline
\end{tabular}

$$
\text { من الجدول ( } 11 \text { ) يتبين ما يأتي : }
$$

1- الارتبـاط المعنوي الموجب ببين زمـن أقصى قوة رد فعل بالاصطدام /ثانيـة ومسـاحة مـا تحت المنحنى /سـ² بالاصطدام يعزوه الباحثان إلى أن الزيادة بزمن أقصى قوة رد فعل / نيوتن بالاصطدام سوف يعقبه زيادة معدل

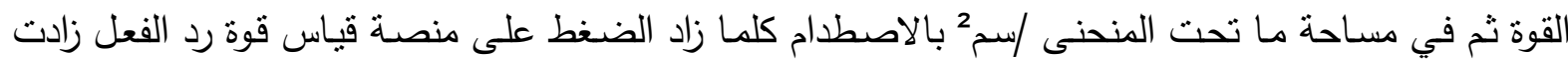
مساحة ما تحت المنحنى وزاد معه زمن أقصى قوة رد فعل في تلك المرحلة والعكس صحيح . ץ- الارتباط المعنوي الموجب ببين زمـن الوصـول إلى أقصسى قوة رد فعل / ثانيـة بالاصطدام ومسـاحة مـا تحت المنحنـى /سم² بالاصــام يعزوه الباحثنان إلى أن زمـن الوصـول إلى أقصى قوة رد فعل /ثانيـة هـ الـزمن المستغرق لتسجيل تلك القوة من قبل منصة قياس قوة رد الفعل ابتداءً من لمس المنصة حتى الوصول إلى أقصى قوة ، فعليه كلما زاد هذا الزمن زادت معه مساحة ما تحت المنحنى في تللك المرحلة والعكس صحيح . 
ب- الارتباط المعنوي الموجب بين زمن أقصى قوة رد فعل / ثانية في مرحلة الاصطدام وزمن الوصول إلى أقصى قوة رد فعل / ثانية في المرحلة ذاتها يعزوه الباحثان إلى أن زمن الوصول إلى أقصى قوة رد فعل / ثانية في إنى

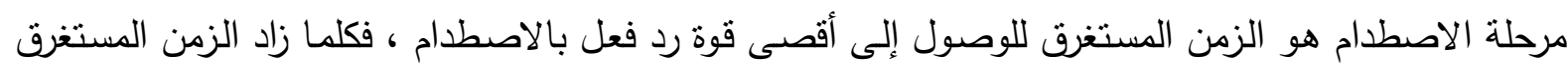

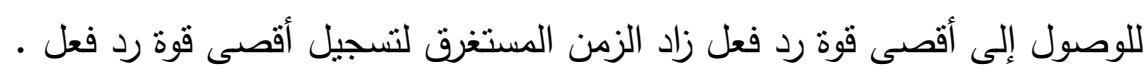

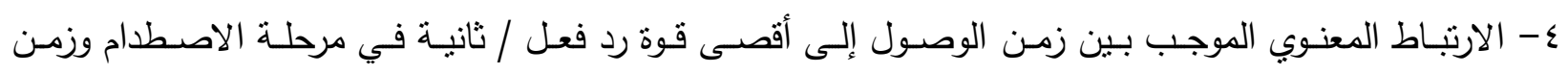
الاصطدام / ثانية يعزوه الباحثان إلى أن زمن الوصول إلى أقصى قوة رد فعل في مرحلة الاصطدام هو جزء من النى

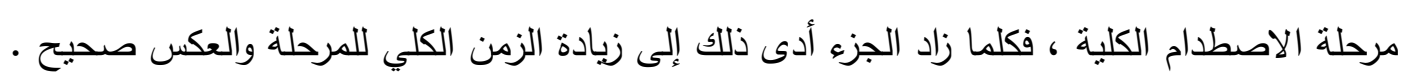
ه- الارتباط المعنوي الموجب بين مساحة ما تحت المنحنى /سم² بالاصطدام وزمن الاصطدام / ثانية بعزوه الباحثان إلى أن زيادة زمن الاصطدام يعمل على زيادة مساحة ما تحت المنحنى /سم² والعكس صحيح.

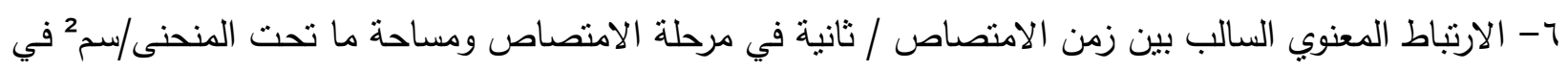
مرحلة الدفع يعزوه الباحثان إلى أن زيادة أو قلة زمن مرحلة الامتصاص سوف يحدد قيمة المرحلة اللاحقة وهي الدفع

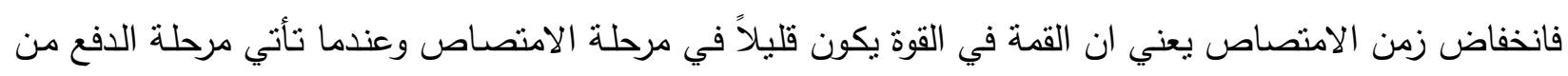

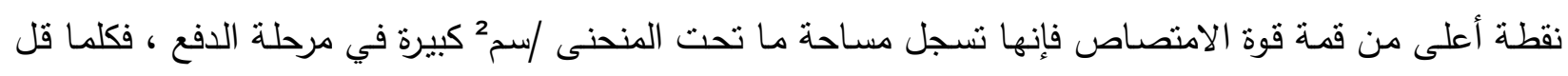

زمن مرحلة الامتصاص سيؤدي ذلك إلى زيادة مساحة ما تحت المنحنى في مرحلة الدفع والعكس صحيح .

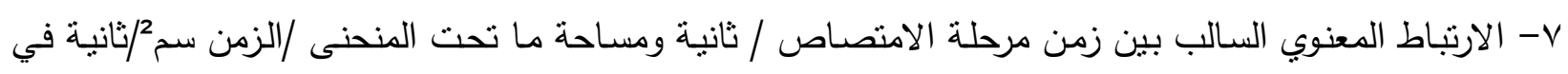

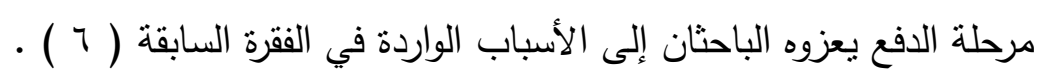

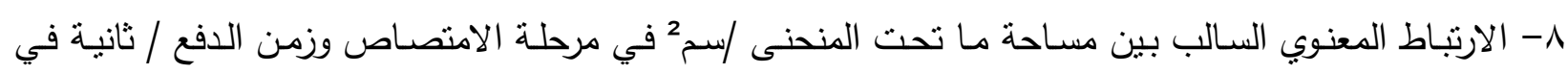

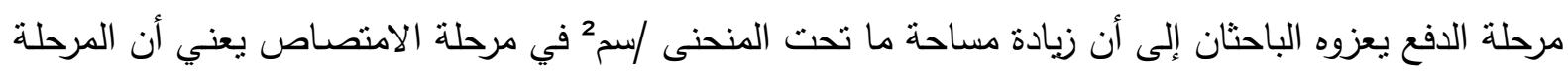

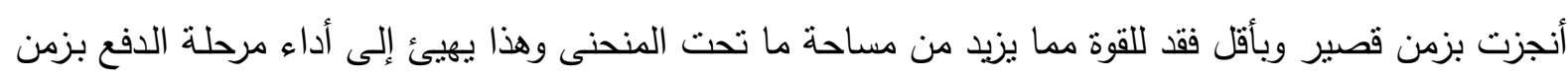

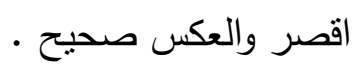

9- الارتباط المعنوي الموجب بين زمن أقصى قوة رد فعل / ثانية في مرحلة الدفع ومساحة ما تحت المنحنى /سم²

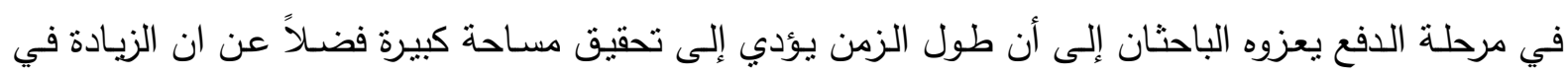

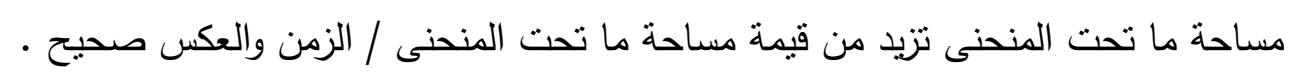

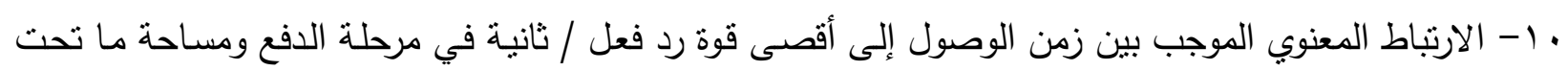

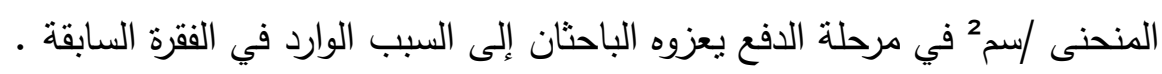

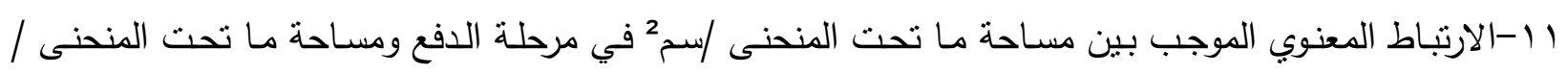
الزمن سم² /نانية في مرحلة الدفع يعزوه الباحثان إلى أن مساحة ما تحت المنحنى /سم² في مرحلة الدفع هي بسط معادلة مساحة ما تحت المنحنى/الزمن،فكلما كبرت مساحة ما تحت المنحنى كبرت مساحة ما تحت المنحنى / الزمن r ا - الارتباط المعنوي السالب بين زمن مرحلة الدفع / ثانية ومؤشر وديع سمير في المرحلة ذاتها يعزوه الباحثان

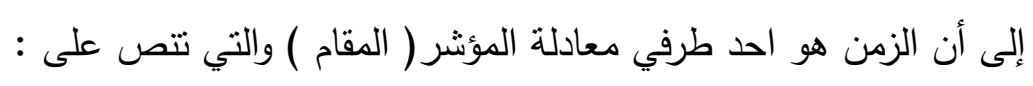
نظام الوزن / مساحة ما تحت المنحنى / الزمن فكلما قل الزمن زادت قيمة المؤشر ولابد من الإثـارة هنا إلى لى

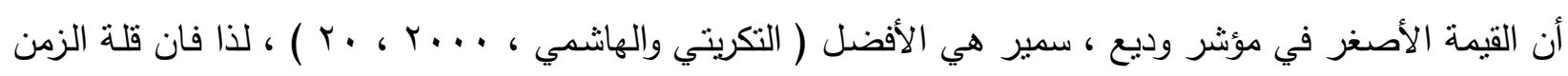

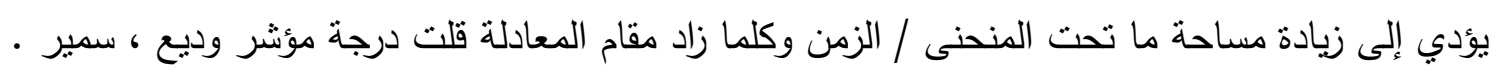




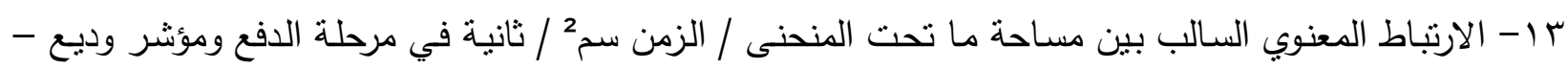

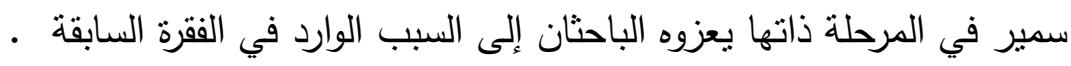

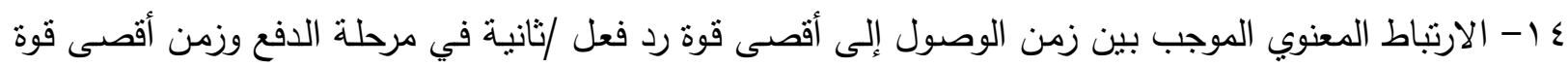

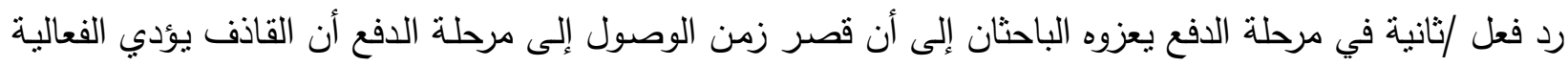

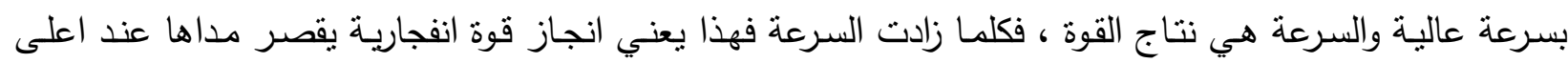

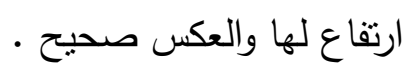

ع - - -ه الارتباطات المعنوية بين المتغيرات الكينماتيكية و متغيرات دالة القوة - الزمن في المرحلة الرئيسة بقذف الثقل بطريقة الزحلقة لعينة البحث :

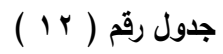

يبين الارتباطات المعنوية بين المتغيرات الكينماتيكية و متغيرات دالة القوة - الزمن في المرحلة الرئيسة بقذف الثقل بطريقة الزحلقة لعينة البحث

\begin{tabular}{|c|c|c|c|}
\hline الاحتمالية & قيمة (ر ) & الارتباطات المعنوية & $\uplus$ \\
\hline$\cdot,+r q$ & $\cdot, 9 \vee 1$ & ارتفاع م.ث.ك الجسم في وضع القوة × زمن أقصى قوة رد فعل في مرحلة الاصطدام & -1 \\
\hline$\cdot,+19$ & $\cdot, 9 \vee 1$ & الاصتفاع م.ث.ك الجسم في وضع القوة × زمن الوصول إلى أقصى قوة رد فعل في مرحلة & $-r$ \\
\hline$\cdot,+19$ & $\cdot, 9 \vee 1$ & ارتفاع م.ث.ك الجسم في وضع القوة × زمن الاصطدام & -4 \\
\hline
\end{tabular}

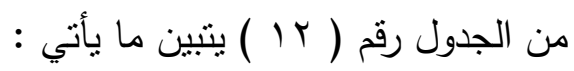

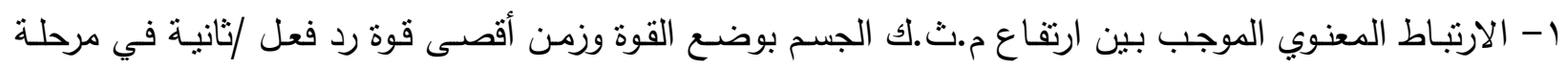

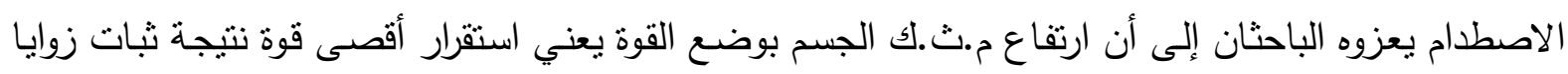

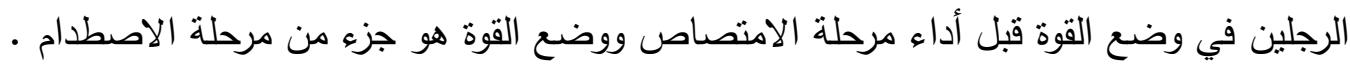

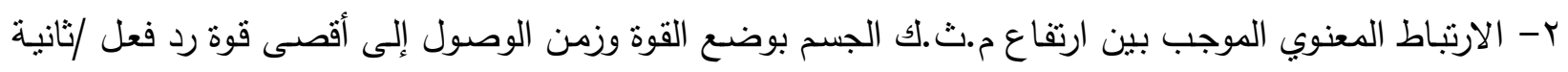

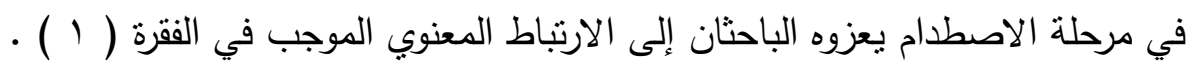

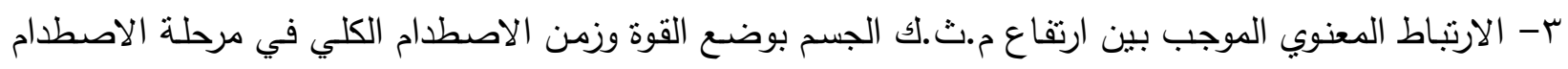

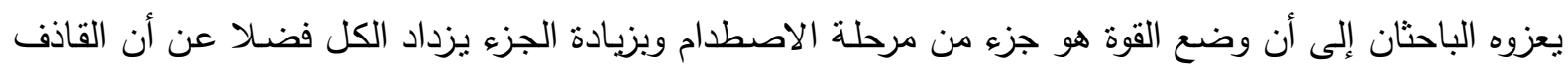

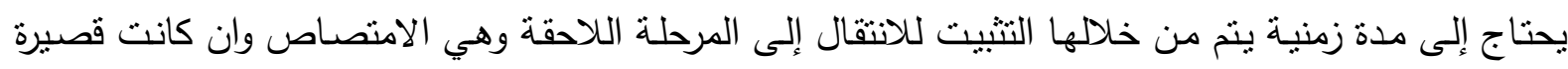

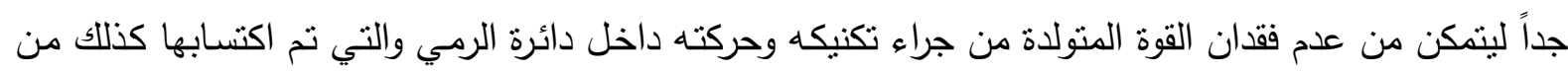
الأرض في وضع القوة والذي هو جزء من مرحلة الاصطدام والذي سيؤثر على كل متغيرات تلك المرحلة ومنها

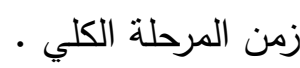

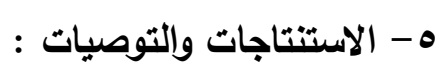

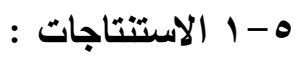

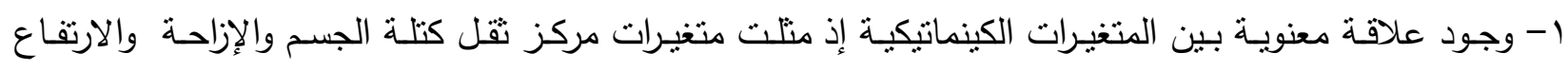

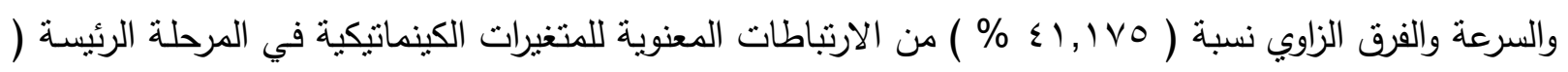

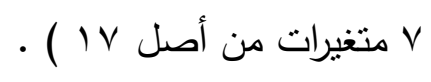


r- وجود علاقة معنوية بين المتغيرات الكينتيكية في الزخم الأفقي والطاقة الحركية الأفقية ومحصلة الزخم والطاقة

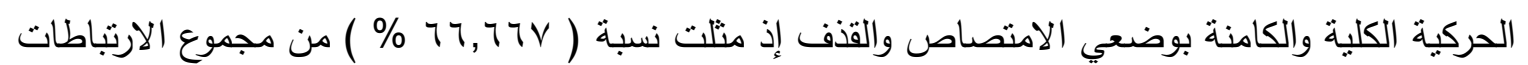

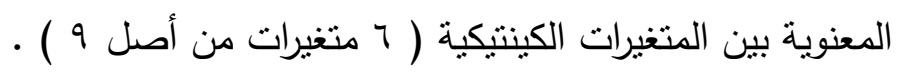

ץ- وجود علاقة معنوية بين المتغيرات الكينماتيكية والكينتيكية إذ كان للإزاحة والسرعة الأفقية ومحصلة الإزاحة مع الكعات محصلة الزخم والزخم العمودي والأفقي لحركة مركز نقل كتلة الجسم والطاقة الحركية العمودية والأفقية ومحصلة الكانة

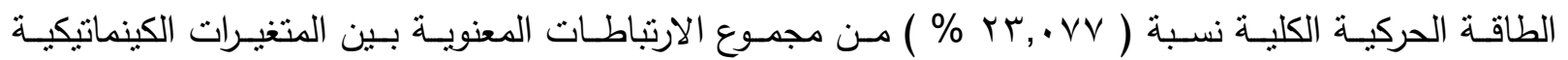

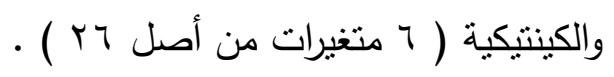

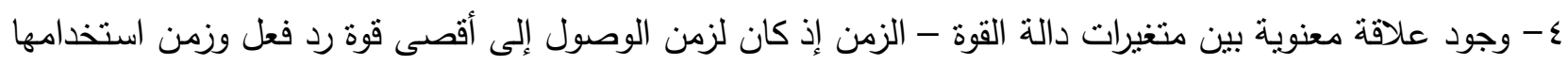

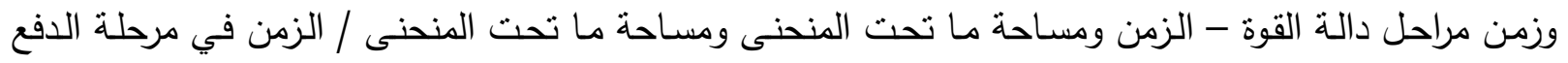

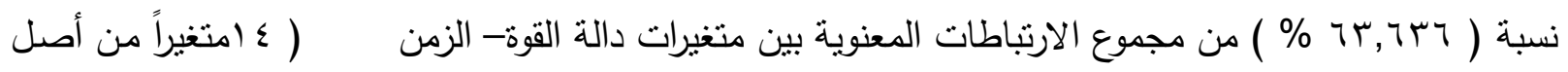
$\cdot(r+$

ه- إن للسرعة الأفقية والفرق الزاوي والارتفاع لـ م.ث.ك الجسم في مراحل الاصطدام ، والامتصاص ،والدفع في

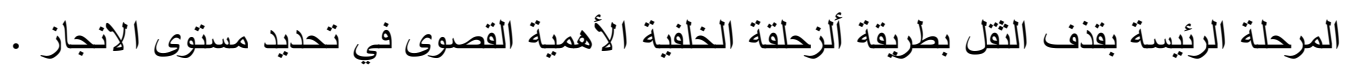

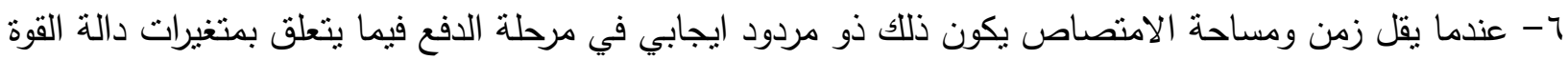
- الزمن - الزمان

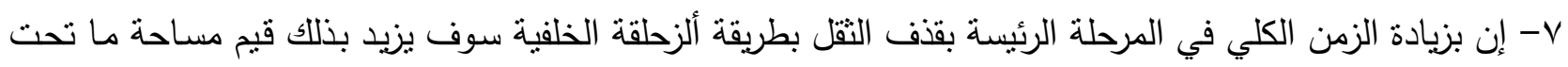
المنحنى / الزمن في كل مرحلة من مراحل ( الاصطدام ، والامتصاص ، والدفع ) مما يشكل عائقاً في الأداء الفني

$$
\text { ه- ون التوصيق الانجاز المطلوب . }
$$

1- التأكيد على انجاز أقصى قوة في مرحلة الدفع المقرون بسرعة الأداء لتحقيق أفضل انجاز في قذف النقل .

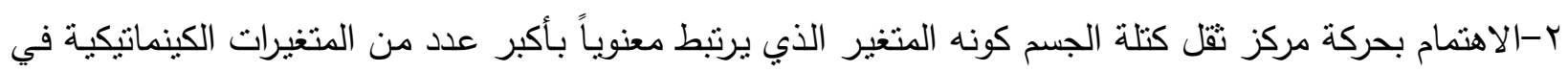

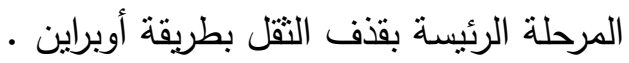
r- تطوير السرعة الزاوية للجسم في مرحلة الدفع لانعكاساتها الايجابية على المسافة الحقيقية لسسار النقل في • الطيران ع- التأكيد على استخدام جانب التصوير الفيديوي والتحليل الحركي من قبل المدربين باستخدام الأجهزة الحديثة

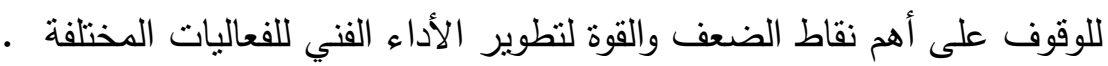

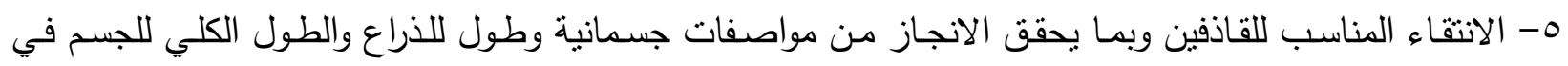
فعالية قذف النقل . 1- على المدربين والعاملين في المجال الرياضـي الاهتمام بمقدار تسليط القوة في مرحلـة الاصطدام وتقليل زمن

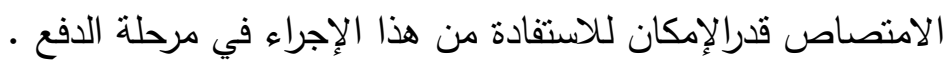

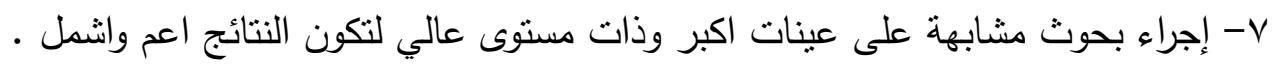


المصادر

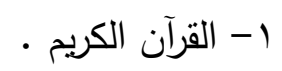

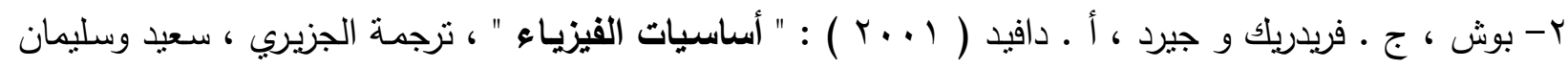

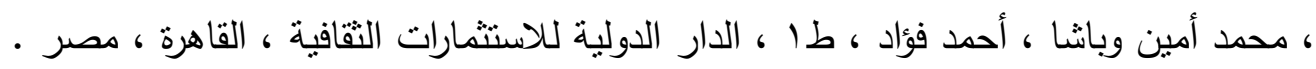

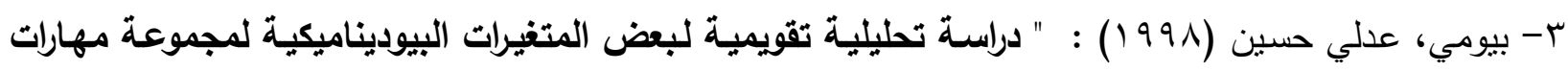
الكب على جهاز المتوازي "، مجلة نظريات وتطبيقات، العدد الواحد والثلاثون، كلية التربية الرياضية للبنين،

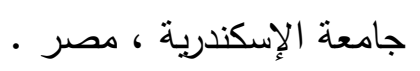

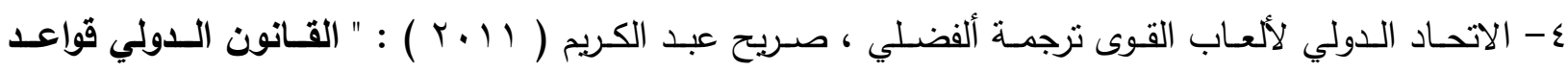

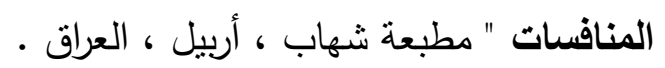

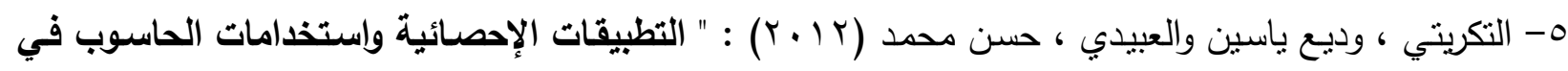

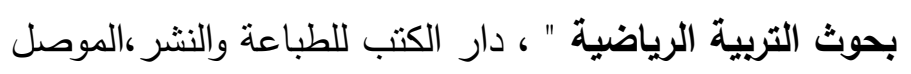

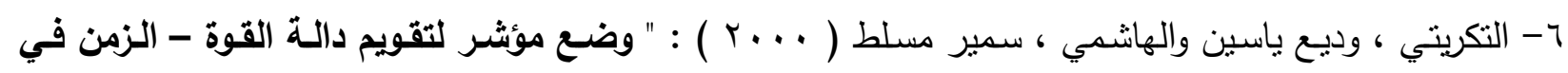

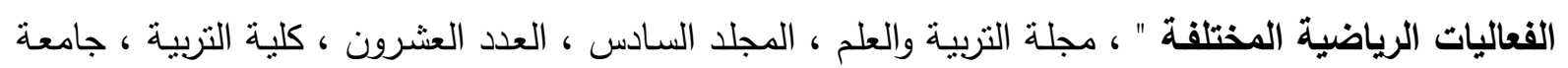

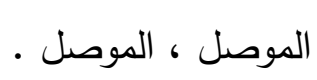

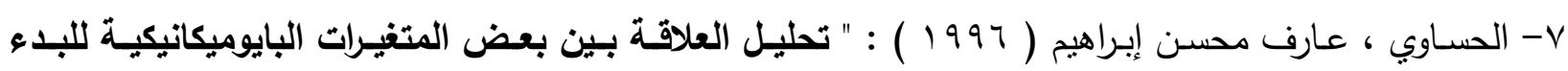

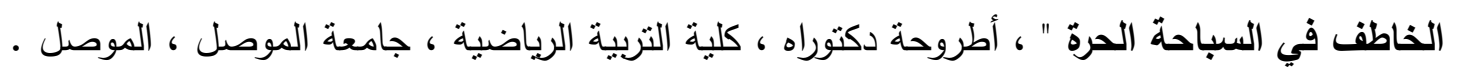

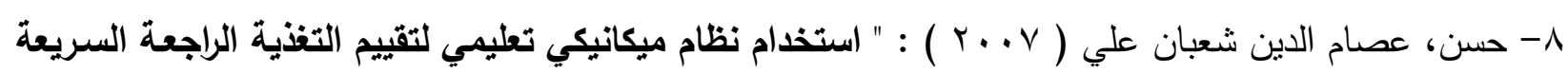

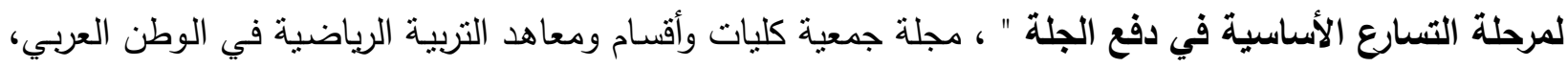

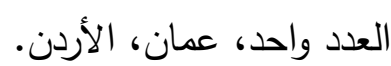
9- حسين ، قاسم حسن ، ومحمود ، إيمان شاكر ( 1991 ) ) : "مبادئ الأسس الميكانيكية للحركات الرياضية " ،

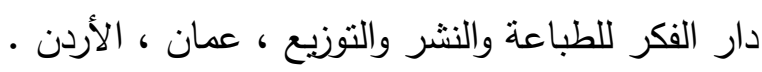

• 1 - ألربضي ، كمال جميل ( 1991 ) ) : " الجديد في العاب القوى " ، الأردئ ، دائرة المطبوعات والنشر ، الأردن .

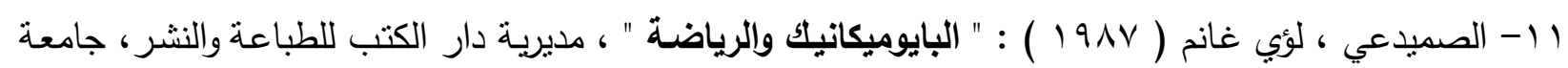

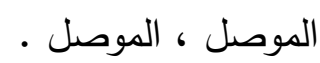
rا - الطالب ، ضياء مجيد ( 1911 ) ) : العدخل إلى الألعاب العشرية للرجال والسباعية للنساء " ، دار الكتب

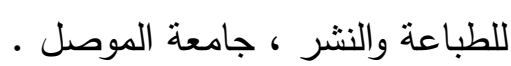

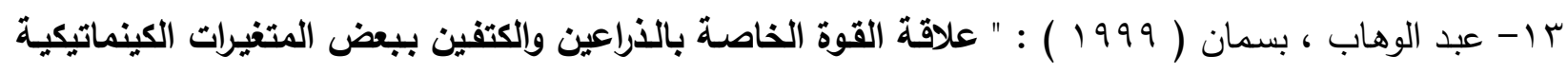

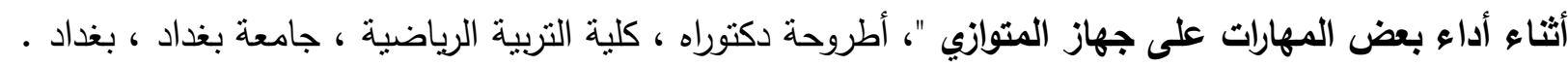

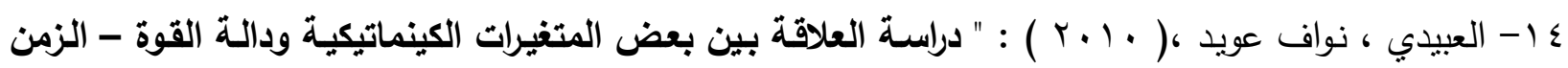

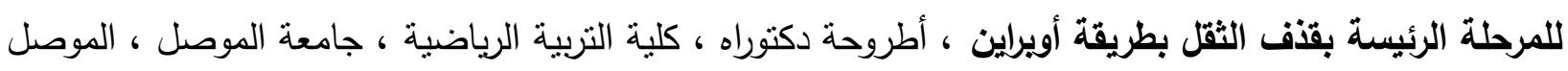

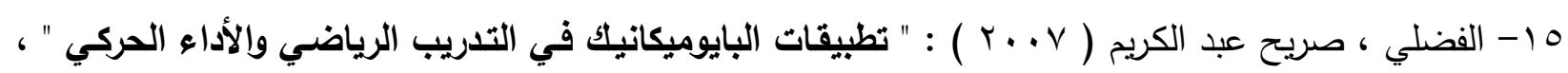

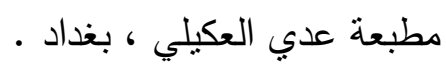
17 - مجيد ، ريسان خريط وشلث ، ، نجاح مهدي (ب9919) : التحليل الحركي ، مطبعة الحكمة ، البصرة . 
V ا - محجوب ، وجيه ( •99 19) : " التحليل الحركي الفيزياوي والفسلجي للحركات الرياضية " ، مطابع التعليم

$$
\text { 1 العالي ، بغداد . محجوب ، وجيه والطالب ، نزار مجيد ( } 191 V \text { ) ) : " التحليل الحركي " مطابع التعليم العالي ، بغداد }
$$

19- Blazevich Anthony (2007); ' Sports Biomechanics The Basics: Optimizing

Human Performance , First published by A\&C Black Publishers Ltd38 Soho Square, London W1D 3HB

20- Deyson , G (1977 ) ; The Mechanics of athletics, London , university of London , press, LTD,

21- Liu Weimin and Wang Mingxaun ( 2008 ) ; Kinematics Analysis of Shot put in Elite Athletes Letes - A Case Study, Jiangsu Research Institute of Sports Science, Nanjing, People's Republic of China

22- Tom pagani (1986 ), Track \& field " The Glide shot put style " ; Fresno state University .

23- Hay .J, G (1978 ) ; The Biomechanics of sport , 2 nd , prentice - Hall, Englewood Cliffs. N . J.

24 - Hall J. Susan (1999), Basic Biomechanics , 3ed , Mc Graw-Hill international editions, edition Boston

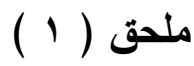

$$
\begin{aligned}
& \text { فريق العمل المساعد في التجريتين الاستطلاعية والرئيسة وإعداد دائرة الرمي }
\end{aligned}
$$

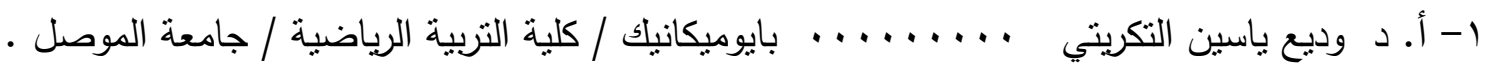

$$
\begin{aligned}
& \text { ץ- م . د نواف عويد عبود . . . . . . . . . . بايوميكانيك / كلية التربية الرياضية / جامعة الموصل . }
\end{aligned}
$$

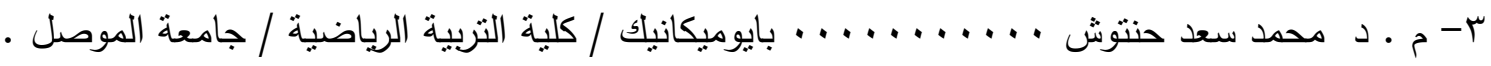

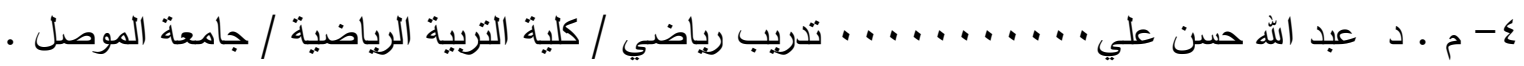

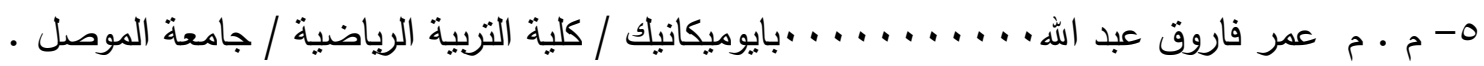

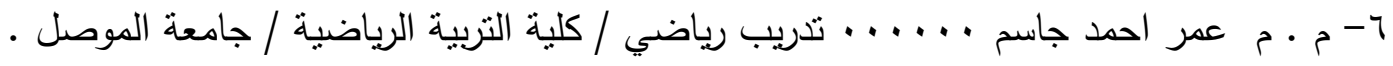

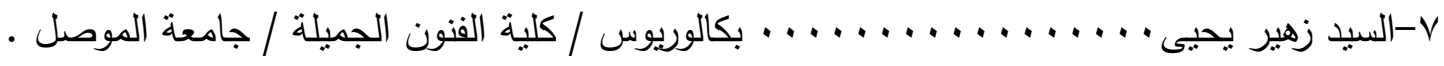

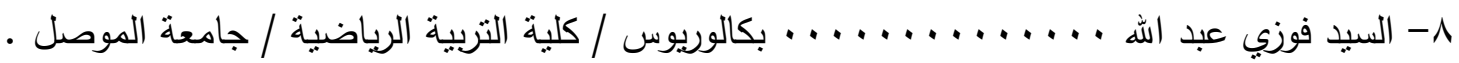


دراسة تملياية لعدد من المتغيرات البايوميكانيكية في المرهلة الرنيسة بقذف.......

ملحق (r)

صور إنشاء دائرة الرمي بمساعدة أعضاء فريق العمل والباحثان
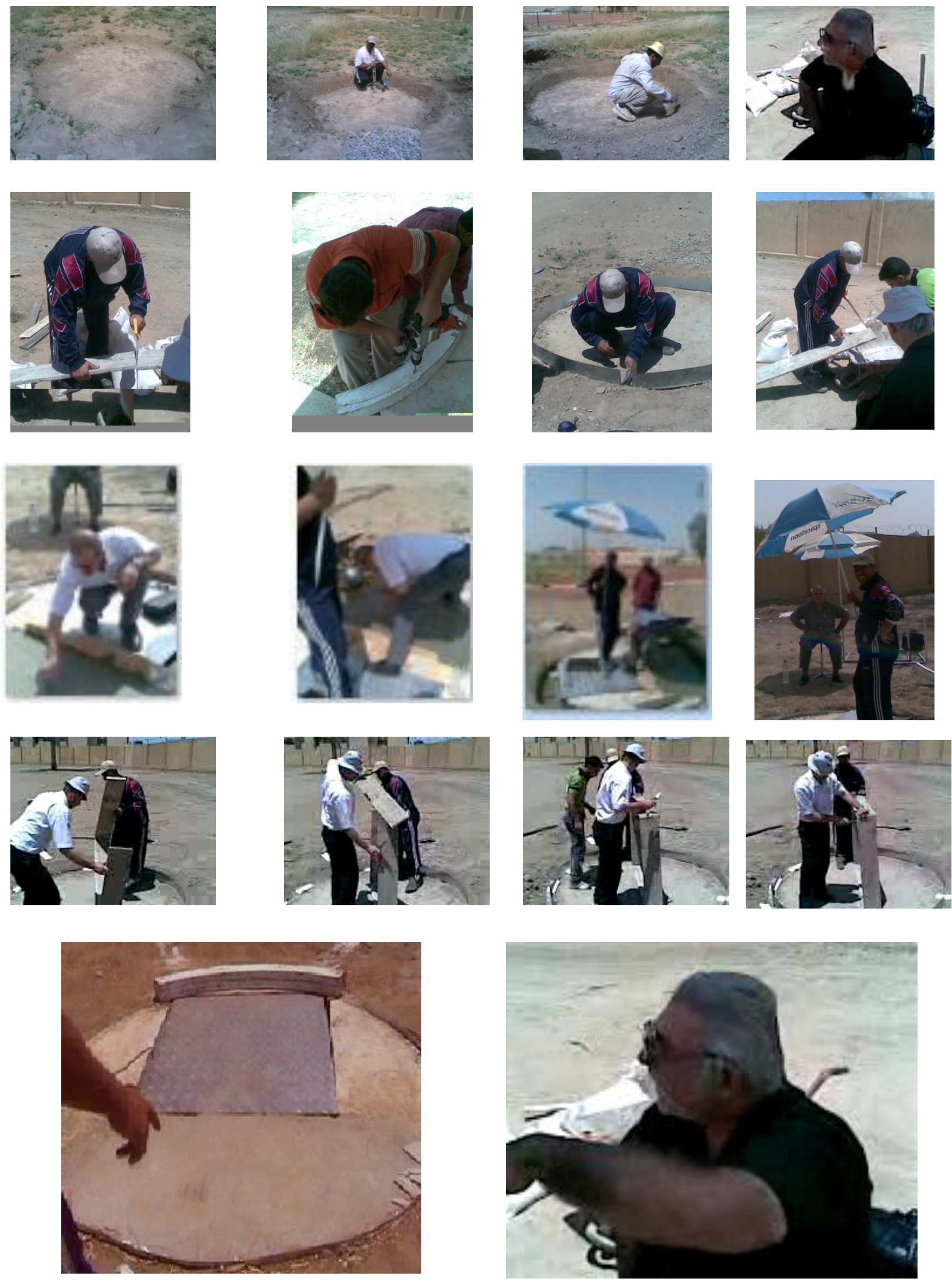


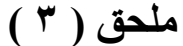

السلسلة الحركية لقذف الثقل بطريقة ألزحلقة الخلفية لأحد أفراد العينة
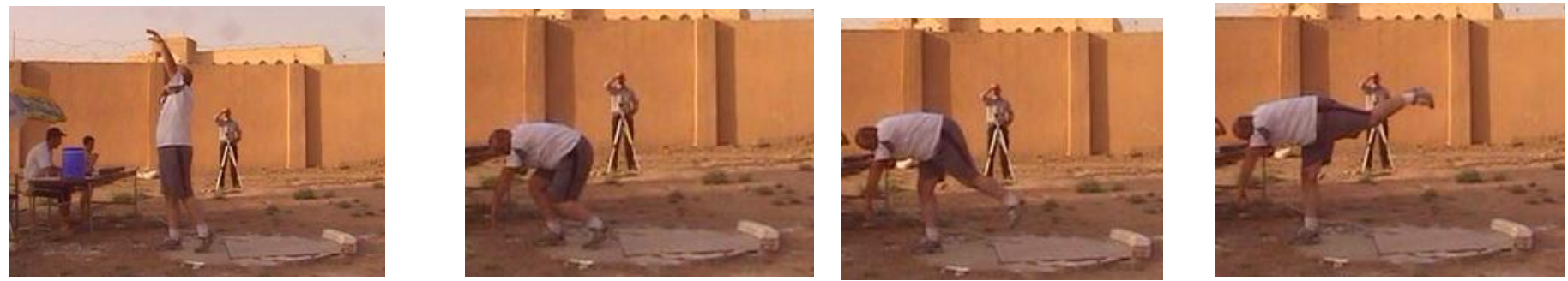

مسك وحمل الثقل و الوضع لابتدائي
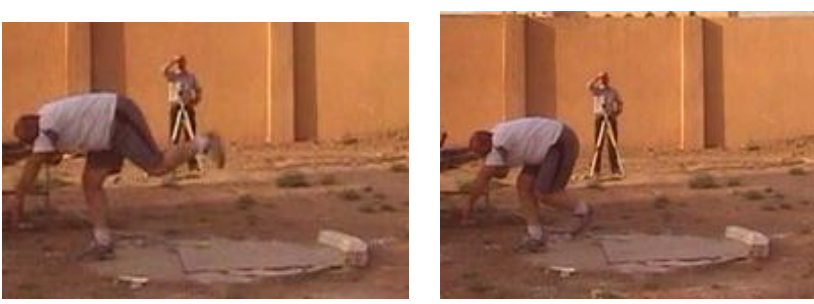

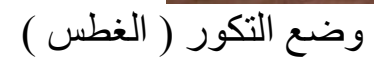
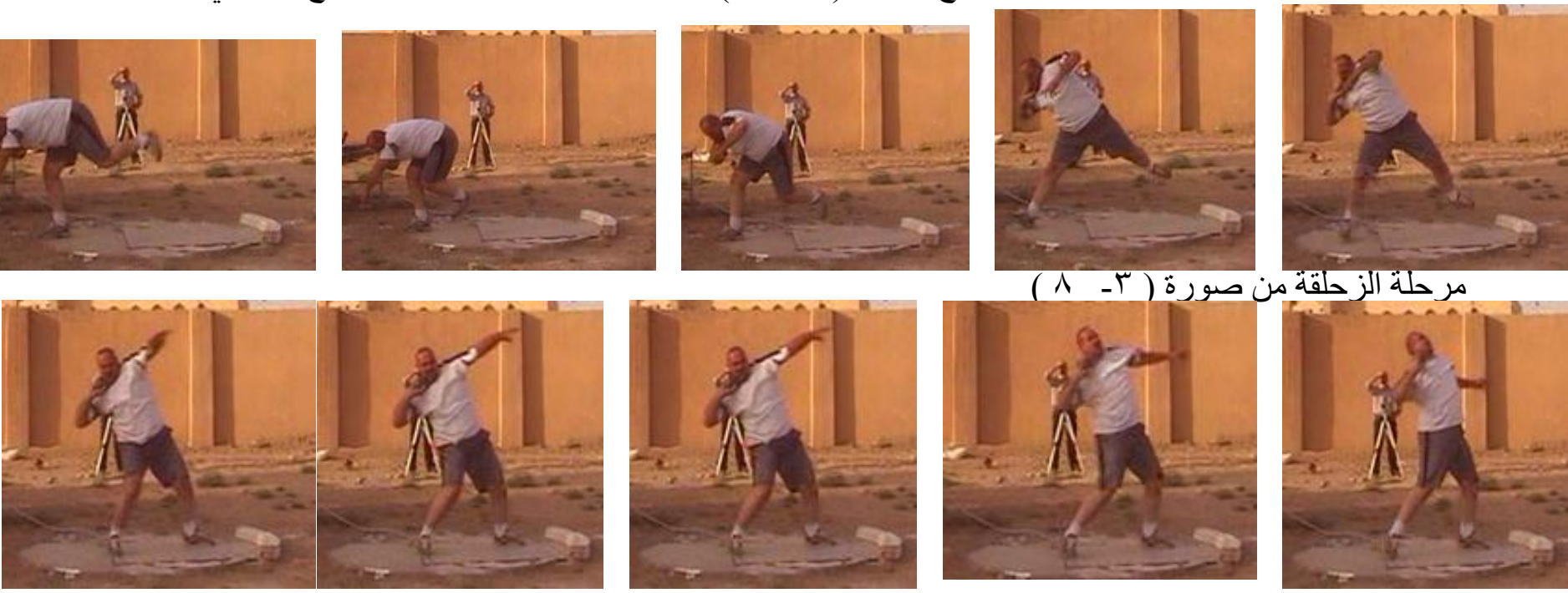

مر حلة الزحلقة من صورة ( ب - 1 ) م

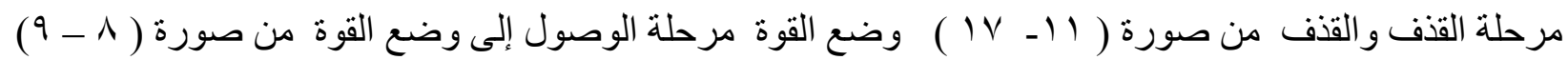
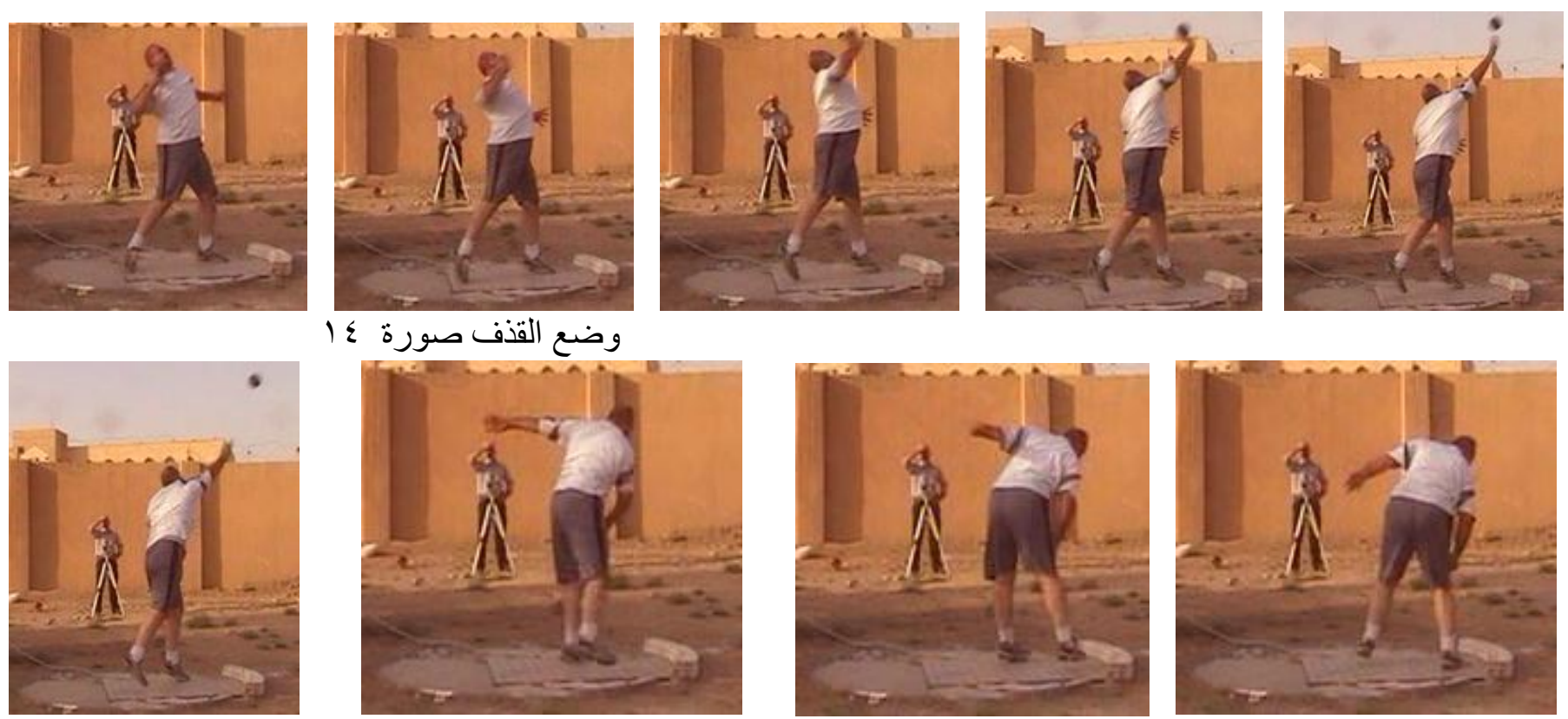

وضع القفت صورة ؟
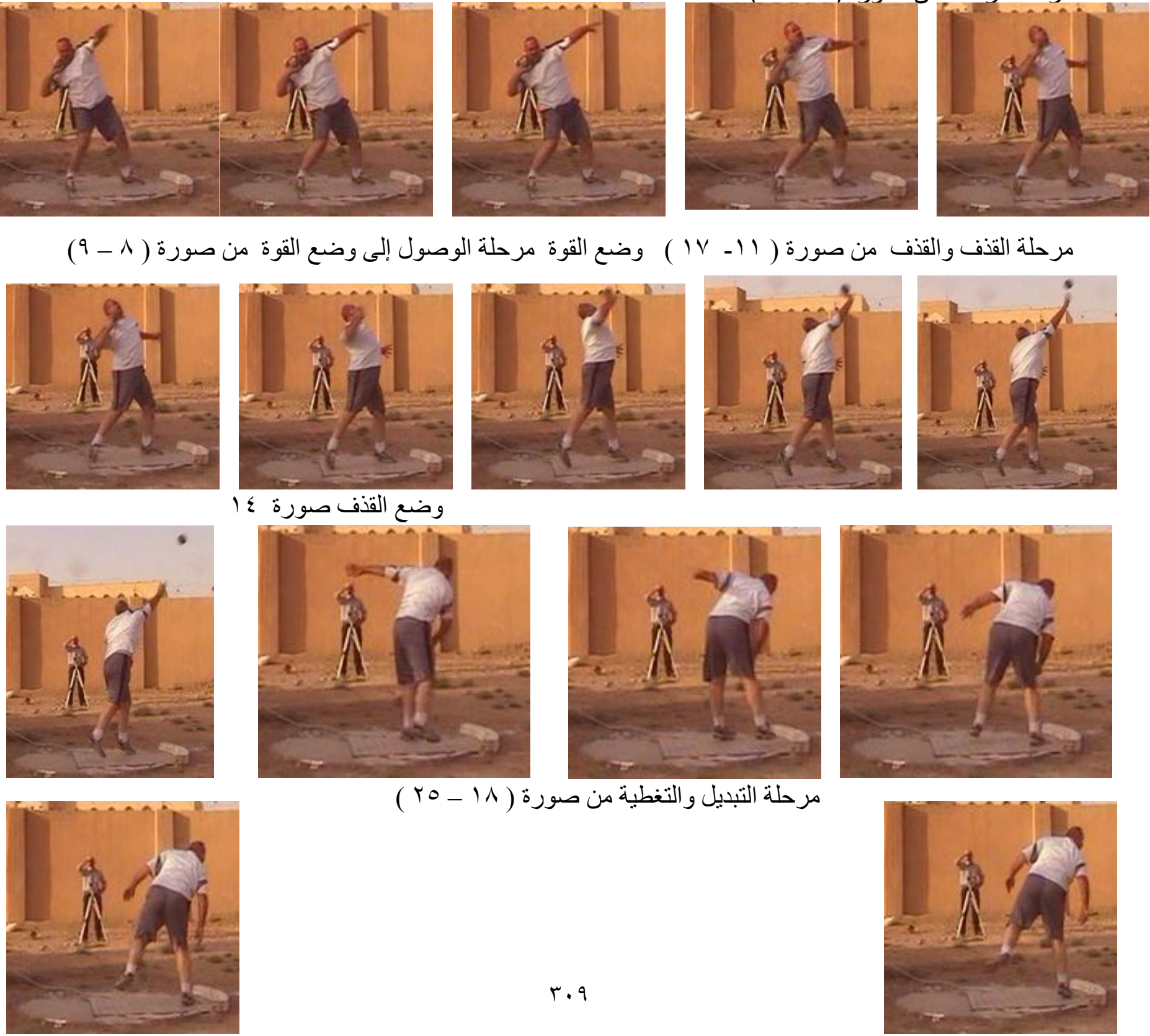

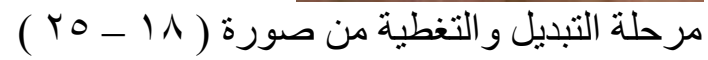

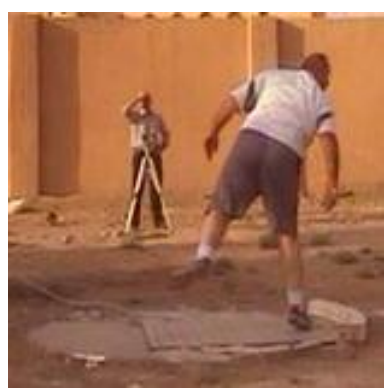

